\title{
Estimates of radiance reflected towards the zenith at the surface of the sea
}

\author{
E. Aas \\ Department of Geosciences, University of Oslo, Norway \\ Received: 6 April 2010 - Published in Ocean Sci. Discuss.: 14 June 2010 \\ Revised: 23 August 2010 - Accepted: 20 September 2010 - Published: 5 October 2010
}

\begin{abstract}
Remote sensing of water colour by ship-mounted sensors represents an important tool for the validation of satellite products and the monitoring of water quality. The recorded radiance from the sea has to be corrected for the surface-reflected radiance from sun and sky in order to obtain the water-leaving radiance. Here the simple case of radiance reflected towards the zenith is studied. A set of observed sky radiance and solar irradiance data from Oslo has been used together with a Gaussian slope distribution for the sea surface in order to estimate the reflected radiance. The spectral range studied is $405-650 \mathrm{~nm}$, the solar zenith angles are in the range $37^{\circ}-76^{\circ}$, and the wind speeds are up to $10 \mathrm{~m} \mathrm{~s}^{-1}$. The analysis of the results show that the reflected radiance has to be separated into three contributions: sky radiance and sun rays reflected at the foam-free surface and irradiance reflected by whitecaps and foam. It is then demonstrated that by using four input values, namely the downward irradiance, the sky radiance from the zenith, the solar zenith angle and the wind speed, it is possible to obtain by simple expressions estimates of the reflected radiance that only differ from the former calculated values by relative errors of less than $5 \%$. The analysis also indicates that for the spectral range studied neither the water-leaving radiance nor the surface-reflected radiance can be disregarded relative to the other one in the Case 2 waters of the Oslofjord-Skagerrak area. The results form a first step towards the study of reflected radiance in viewing angles differing from the nadir direction.
\end{abstract}

\section{Introduction}

Radiometric systems mounted on ships of opportunity have in recent years become an important tool for automatic monitoring of water quality. Real-time data are collected from

Correspondence to: E. Aas

(eyvind.aas@geo.uio.no) several ferries in Norwegian coastal waters and adjacent areas (http://www.niva.no - Ferrybox monitoring). The analysis of these data require simple and accurate methods for the correction of the reflected radiance. Several studies have been made to develop such methods and to optimize the viewing angles of the radiometers with regard to the sun in order to avoid sun glints, with very satisfactory results. Mobley (1999) recommends $40^{\circ}$ as the vertical angle and $135^{\circ}$ as the azimuth angle away from the sun, while Fougnie et al. (1999) and Deschamps et al. (2004), using a polarizer, suggest $45^{\circ}$ for the vertical (near the Brewster angle) and $135^{\circ}$ for the azimuth. In the NASA protocols (Mueller et al., 2003) it is recommended that the azimuth viewing angle is in the range $90^{\circ}-135^{\circ}$ away from the sun, and that the nadir angle is $40^{\circ}-45^{\circ}$, in order to avoid sun glints. Hooker et al. (2002) and Zibordi et al. $(2002,2004,2009)$ apply a $40^{\circ}$ vertical angle and a $90^{\circ}$ azimuth, while Ruddick et al. (2006) use $40^{\circ}$ for the vertical and $140^{\circ}$ for the azimuth. However, the ferries have to follow fixed courses, implying that the azimuth angles may deviate from the optimal ones, and part of the time the sun may obtain positions where sun glints are likely to contribute significantly to the recorded radiance. Simple methods that may correct for both sky and sun glints have not yet been established.

A ship-mounted radiance sensor looking down at the surface of the sea receives a radiance $L_{\mathrm{r}}$ consisting of light from the sky and sun reflected upwards at the surface, and a waterleaving radiance $L_{\mathrm{w}}$ consisting of light scattered upwards from different depths within the body of the water and transmitted through the water-air interface. Only the radiance $L_{\mathrm{w}}$ carries with it information about the optical properties of the water mass. If $L_{\mathrm{r}}$ can be estimated, then $L_{\mathrm{W}}$ can be found from the recorded total radiance $L_{\mathrm{r}}+L_{\mathrm{w}}$. One of the goals of remote sensing and marine optics is to develop methods by which it will be possible to determine the contents of optical components and the parameters of water quality from analysis of the water-leaving radiance.

Published by Copernicus Publications on behalf of the European Geosciences Union. 
The reflected radiance $L_{\mathrm{r}}$ is influenced by the wind speed, since the wind roughens the surface and eventually produces whitecaps and foam. The water-leaving radiance $L_{\mathrm{w}}$, on the other hand, is practically independent of the wind, as will be demonstrated later in this paper. The relationship between wind speed and sea state was included in the Beaufort wind scale a century ago. The scale defines very characteristic features of the sea that are important for marine remote sensing. At Beaufort force 0 (calm, wind speed up to $0.3 \mathrm{~m} \mathrm{~s}^{-1}$ ), the sea is flat. Ripples start to form at force 1 (light air, $0.3-1.5 \mathrm{~m} \mathrm{~s}^{-1}$ ), and small wavelets are formed at force 2 (light breeze, $1.5-3.3 \mathrm{~m} \mathrm{~s}^{-1}$ ). Wave crests start breaking at force 3 (gentle breeze, $3.3-5.5 \mathrm{~m} \mathrm{~s}^{-1}$ ), producing scattered whitecaps, and the amount of whitecaps and foam increases at forces 4 and 5 (moderate and fresh breeze, 5.5$8 \mathrm{~m} \mathrm{~s}^{-1}$ and $8.0-11.0 \mathrm{~m} \mathrm{~s}^{-1}$ ). In this paper the range of wind speed from 0 to $10 \mathrm{~m} \mathrm{~s}^{-1}$ is studied, since data from situations with stronger winds are not likely to be used.

The purpose of the present study is to see how $L_{\mathrm{r}}$ in the Skagerrak-Oslofjord area acts as a function of the solar zenith angle, the wind speed and the wavelength of light, and to determine if it is possible to estimate $L_{\mathrm{r}}$ with acceptable accuracy by indirect methods in the case when $L_{\mathrm{r}}$ may be influenced by both sky and sun glints. Consequently the study is made as simple as possible, and the models for the statistical distribution of surface slope and for the influence of foam and whitecaps are chosen according to this principle. Because it simplifies the calculations only the radiance reflected towards zenith is studied. The reflected radiance $L_{\mathrm{r}}$ is decomposed into three parts: the reflected sky radiance or sky glints $L_{\mathrm{r} \text {,sky }}$, the reflected sun glints $L_{\mathrm{r} \text {,sun }}$, and the light

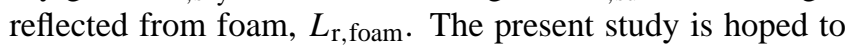
represent a first step toward methods of correction for other viewing angles that may involve sun glints.

Possible values of the ratio $L_{\mathrm{w}} / L_{\mathrm{r}}$ are also investigated, because if $L_{\mathrm{w}} / L_{\mathrm{r}} \ll 1$, the accuracy of the estimated $L_{\mathrm{w}}$ will be too small to render $L_{\mathrm{W}}$ useful, and if $L_{\mathrm{w}} / L_{\mathrm{r}} \gg 1$, the influence of $L_{\mathrm{r}}$ on the recorded upward radiance can be neglected. However, while the magnitude of $L_{\mathrm{w}}$ is influenced by the optical properties of both the atmosphere and the sea, $L_{\mathrm{r}}$ is only influenced by the atmospheric properties. These two sets of optical properties are in no way correlated. Also the two data sets for $L_{\mathrm{r}}$ and $L_{\mathrm{w}}$ are independent and differ in time and space. Consequently, in order to make $L_{\mathrm{r}}$ and $L_{\mathrm{w}}$ comparable, they are normalized against the total downward irradiance $E_{\text {tot }}$ from sun and sky in air and then $L_{\mathrm{w}} / L_{\mathrm{r}}$ is estimated from the ratio of $L_{\mathrm{w}} / E_{\mathrm{tot}}$ and $L_{\mathrm{r}} / E_{\mathrm{tot}}$.

\section{Theoretical relationships and data material}

\subsection{The statistical distribution of slopes}

The first comprehensive investigation of reflected light from a roughened sea surface was probably conducted by Cox and
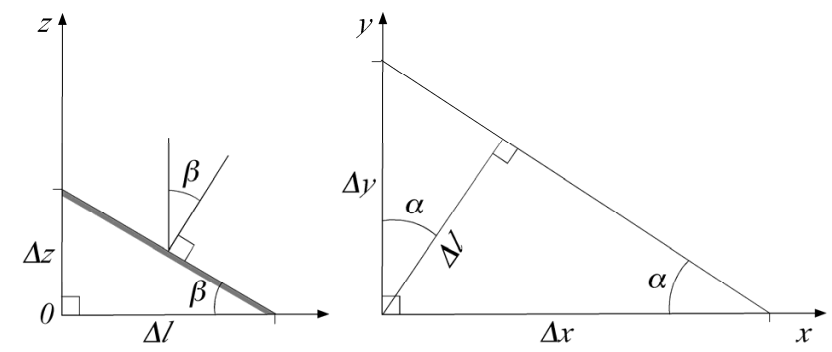

Fig. 1. Left: Vertical section in the steepest direction of the sloping surface. The grey line indicates the surface. Right: Projection of the sloping surface into the horizontal $x-y$ plane at $z=0$.

Munk (1954a, b). Recently Munk has pointed out several problems related to the roughness of the sea (Munk, 2009). A detailed discussion together with further references can be found in Walker (1994).

We will apply the notation of Cox and Munk (1954a, b) whenever practical. Let $x$ designate the crosswind coordinate, $y$ the upwind coordinate, and $z$ the elevation of the surface, where $z=0$ describes the ocean at rest. Assume that a part of the surface is inclined relative to the horizontal surface, and let this part have an area vector of unit length at right angles to the area. This vector makes an angle $\beta$ with the $\mathrm{z}$ axis (Fig. 1), and $\beta$ is also the angle between the surface and the horizontal plane $z=0$. The projection of the area vector into the $x-y$ plane has an azimuth angle $\alpha$ with the $y$ axis, where $\alpha$ is positive to the right of the upwind direction (Fig. 1). The direction of the projected area vector is then the direction where the slope is steepest. The slope of the inclined surface becomes $m=\tan \beta$. Let $\Delta l$ be the projection of the area vector into the $x-y$ plane (Fig. 1) and $\Delta z$ a height on the $z$ axis, related to $m$ and $\Delta l$ by

$\frac{\Delta z}{\Delta l}=m=\tan \beta$.

A line normal to $\Delta l$ intersects the $x$ and $y$ axes at the two points

$\Delta x=\Delta l / \sin \alpha, \quad \Delta y=\Delta l / \cos \alpha$.

The slopes of the surface in the $x$ and $y$ directions can be written by combining Eqs. (1) and (2)

$z_{x}=\frac{\partial z}{\partial x}=\frac{\Delta z}{\Delta x}=\frac{\Delta z}{\Delta l} \sin \alpha=m \sin \alpha$,

$z_{y}=\frac{\partial z}{\partial y}=\frac{\Delta z}{\Delta y}=\frac{\Delta z}{\Delta l} \cos \alpha=m \cos \alpha$.

Evidently the sum of the two squared slopes $z_{x}^{2}$ and $z_{y}^{2}$ becomes

$z_{x}^{2}+z_{y}^{2}=m^{2}\left(\sin ^{2} \alpha+\cos ^{2} \alpha\right)=m^{2}$.

The mean values of the slopes in this equation can be written

$\overline{z_{x}^{2}}+\overline{z_{y}^{2}}=\sigma_{c}^{2}+\sigma_{u}^{2}=\overline{m^{2}}=\sigma^{2}$, 
where $\sigma_{c}^{2}$ and $\sigma_{u}^{2}$ are the mean square slopes in the crosswind $(x)$ and upwind $(y)$ directions, and $\sigma^{2}$ the mean square slope.

Cox and Munk found from observations of sun glitter that the statistical distribution of slopes in the $x$ and $y$ directions almost followed a two-dimensional Gaussian probability function. Their complete mathematical description can be simplified to a more approximate expression, and the distribution then becomes the Gaussian function

$p\left(z_{x}, z_{y}\right) \approx \frac{1}{2 \pi \sigma_{c} \sigma_{u}} \exp \left[-\frac{z_{x}^{2}}{2 \sigma_{c}^{2}}-\frac{z_{y}^{2}}{2 \sigma_{u}^{2}}\right]$.

The slopes $z_{x}$ and $z_{y}$ have positive and negative values, and their mean values are zero. The double integral of $p d z_{x}, d z_{y}$ between $-\infty$ and $+\infty$ along both horizontal axes is equal to 1.

In the data set obtained by Cox and Munk the ratio $\sigma_{c}^{2} / \sigma_{u}^{2}$ varied in the range $0.54-1.0$ with a mean value of 0.75 . The mean square slopes were linear functions of the wind speed $W$ :

$\sigma_{c}^{2}=0.003+0.00192 W$,

$\sigma_{u}^{2}=0.000+0.00316 W$

where $W$ is the wind speed in $\mathrm{ms}^{-1}$. The mean square slope $\sigma^{2}$ was observed to be

$\sigma^{2}=\sigma_{c}^{2}+\sigma_{u}^{2}=0.003+0.00512 W$.

The light reflected toward the zenith arrives from all azimuthal directions, and the measurements of radiance from the surface of the sea are taken for different azimuthal directions of the Sun. The probability distribution of the slopes has therefore been simplified to the one-dimensional case

$p(m)=\frac{d N}{d m} \approx \frac{1}{(2 \pi)^{0.5} \sigma} \exp \left[-\frac{m^{2}}{2 \sigma^{2}}\right]$,

where $d N$ is the fractional number of slopes of value $m$ per slope unit $d m$. If we introduce the normalized slope

$s=m / \sigma$,

the Gauss function obtains the form

$p(s)=\frac{d N}{d s} \approx \frac{1}{(2 \pi)^{0.5}} \exp \left[-\frac{s^{2}}{2}\right]$

The integral of $p d s=d N$ for $s$ between $-\infty$ and $+\infty$ is equal to 1 . The cumulated probability of the normalized slope being in the interval from $-\infty$ to $s$ is expressed by

$P(s)=\int_{-\infty}^{s} p\left(s^{\prime}\right) d s^{\prime}=\int_{-\infty}^{s} \frac{1}{(2 \pi)^{0.5}} \exp \left[-\frac{s^{\prime 2}}{2}\right] d s^{\prime}$ and according to Abramowitz and Stegun (1970, eq. 26.2.17)

$P(s)$ can be approximated by

$P(s) \approx 1-p(s)\left[b_{1} t+b_{2} t^{2}+b_{3} t^{3}+b_{4} t^{4}+b_{5} t^{5}\right]$

where $t=\frac{1}{1+0.2316419 s}$

$b_{1}=0.319381530 ; b_{2}=-0.356563782 ; b_{3}=1.781477937$;

$b_{4}=-1.821255978 ; b_{5}=1.330274429$; with an error < $10^{-7}$.

A radiance from the zenith angle $\theta$ has an angle of incidence $i$ at the surface and an angle of reflection $r$, where $i=r$. If the radiance is reflected towards zenith, then the sum $i+r$ is equal to $\theta$, or $\theta / 2=i=r$. Moreover, the slope of the surface producing this reflection must have a slope angle $\beta=i=r=\theta / 2$, as shown by Fig. 2. This means that slopes reflecting radiance towards zenith cannot be steeper than $\beta=45^{\circ}$, and that $s$ in our case is related to $\theta$ by

$s=\frac{m}{\sigma}=\frac{\tan \beta}{\sigma}=\frac{\tan (\theta / 2)}{\sigma}$.

The cumulative probability distribution for $s$ being in the interval from $-s$ to $s$ is expressed by $P(s)-P(-s)$. This distribution is presented in Fig. 3 for the wind speeds $0,2,5$ and $10 \mathrm{~m} \mathrm{~s}^{-1}$. Rather than using $s$ as the variable along the horizontal axis, the related zenith angle $\theta$ of Eq. (15) has been applied. We see that $90 \%$ of the slopes reflecting radiance towards zenith corresponds approximately to directions of $\theta \leq 10^{\circ}, 20^{\circ}, 30^{\circ}$ and $40^{\circ}$ for the increasing wind speeds. That is, the higher the wind speed, the more parts of the sky contribute to the reflected radiance towards the zenith.

The upward radiance below the surface that is refracted and transmitted through the sloping surface towards zenith as the water-leaving radiance must have an angle $j$ in water, relative to the normal to the surface, so that the corresponding refracted ray in air obtains the angle $\beta=r$ relative to the normal to the surface (Fig. 2). The relationship between $j$ and $\beta$ is expressed by Snell's Law:

$\sin \beta=\sin r=n \sin j$,

where $n$ is the refractive index of sea water. Fig. 2 shows that the zenith-directed radiance in air has a nadir angle in water, $\theta_{\mathrm{w}}$, related to $\beta$ and $j$ by

$\theta_{\mathrm{w}}=\beta-j=\beta-\arcsin \left(\frac{\sin \beta}{n}\right)$.

The corresponding cumulative distribution function $P(s)-$ $P(-s)$ is shown in Fig. 4 for the wind speeds $0,2,5$ and $10 \mathrm{~m} \mathrm{~s}^{-1}$, as a function of the nadir angle in water, $\theta_{\mathrm{w}}$. This angle is related to the normalized slope sby Eqs. (15-17). The figure demonstrates that for wind speeds up to $10 \mathrm{~m} \mathrm{~s}^{-1}$, $90 \%$ of the water-leaving radiance with a direction towards zenith is coming from nadir angles in water less than $6^{\circ}$. 


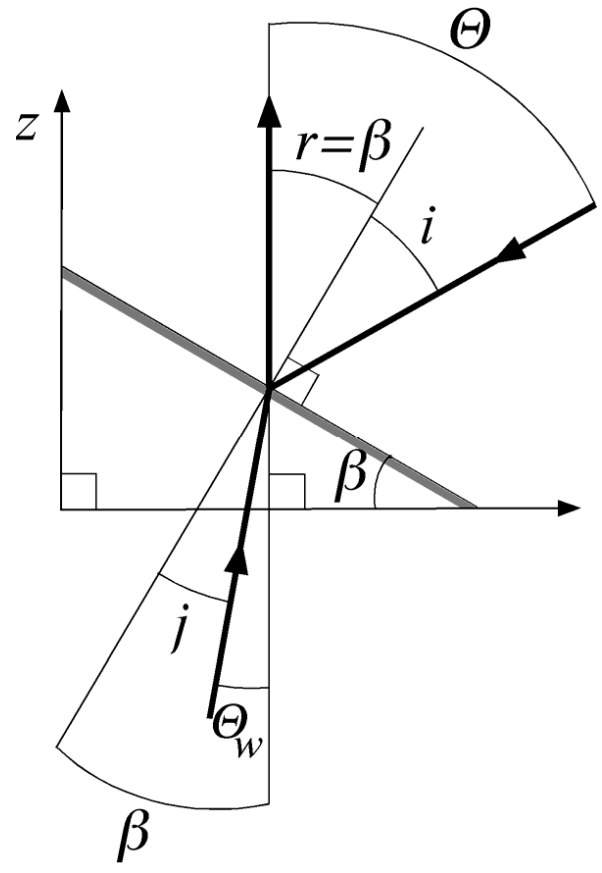

Fig. 2. Vertical section in the steepest direction of the sloping surface, indicated by the grey line. A ray from the zenith angle $\theta$ in the sky has an angle of incidence $i$ and is reflected towards zenith in an angle of reflection $r$ equal to $i$ and slope angle $\beta$. A ray from the nadir angle $\theta_{\mathrm{W}}$ in the sea has an angle of incidence $j$ and is refracted through the surface at an angle of refraction $r$ with a direction towards zenith.

\subsection{Calculation of reflected sky radiance and sun glitter at the foam-free surface}

For the present study it is useful to separate the reflected radiance $L_{\mathrm{r}}$ into the part consisting of reflected radiance from the sky, $L_{\mathrm{r}, \mathrm{sky}}$, the part consisting of reflected solar rays, termed the sun glitter, $L_{r \text {,sun }}$, and the part consisting of reflected radiance from both sky and sun, $L_{\mathrm{r} \text {,foam, }}$, reflected at the foamcovered parts of the surface. We will start by discussing the two first terms, since these are both functions of the slope distribution. Azimuthal mean values $L$ of the sky radiance have been used since the slopes contributing to the reflected radiance are supposed to be oriented at random. The mean radiances were originally observed for the zenith angles $0^{\circ}-$ $15^{\circ}-30^{\circ}-45^{\circ}-60^{\circ}-75^{\circ}$ by Høkedal and Aas (1998) and presented in tables.

From these tabulated values the mean radiances for each degree in the intervals have been interpolated, and in the range $\theta=75^{\circ}-90^{\circ}$ it has been assumed that the radiance is equal to $L\left(75^{\circ}\right)$. Then the mean values of $L$ for the $\theta$ intervals $0^{\circ}-1^{\circ}, 1^{\circ}-2^{\circ}, 2^{\circ}-3^{\circ}, \ldots 89^{\circ}-90^{\circ}$ have been calculated. A small increase of $\theta$ by $\Delta \theta=1^{\circ}$ corresponds to an increase of $\beta$ by $\Delta \beta=0.5^{\circ}$. Consequently the series $\theta=0^{\circ}, 1^{\circ}, 2^{\circ}, \ldots 90^{\circ}$ has a series of reflecting surfaces with angles $\beta=0^{\circ}, 0.5^{\circ}, 1^{\circ}$,

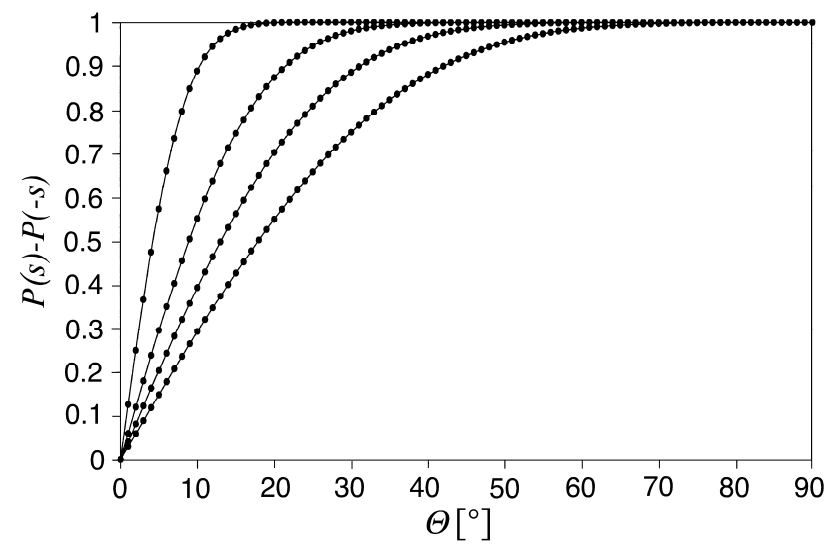

Fig. 3. The cumulative probability $P(s)-P(-\mathrm{s})$ as a function of the zenith angle $\theta$ in air corresponding to $s$. The curves represent from top to bottom the wind speeds $0,2,5$ and $10 \mathrm{~m} \mathrm{~s}^{-1}$.

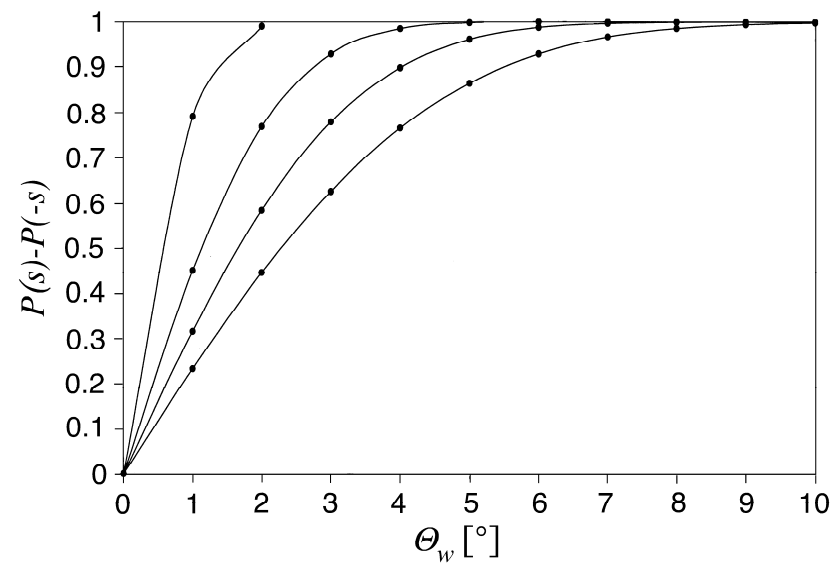

Fig. 4. The cumulative probability $P(s)-P(-\mathrm{s})$ as a function of the nadir angle $\theta_{\mathrm{W}}$ in water corresponding to $s$. The curves represent from top to bottom the wind speeds $0,2,5$ and $10 \mathrm{~m} \mathrm{~s}^{-1}$.

$1.5^{\circ}, \ldots 45^{\circ}$. This produces a series of $m$ by Eq. (1) and for a fixed wind speed a series of $s$ by Eq. (11). The values of $P(s)$ have then been calculated for this series of $s$ values. The probability $\Delta P$ that $s$ should be in the interval from $s_{n-1}$ to $s_{n}$ is obtained by the subtraction

$\Delta P=P\left(s_{n}\right)-P\left(s_{n-1}\right)$.

Thus for each interval $\theta \pm \Delta \theta / 2$ there is a slope $s$ that is able to reflect the radiance $L(\theta)$ towards the zenith, and $\Delta P$ is the weighting function for the radiance from $\theta$. Instead of taking into account the negative values of $s$, only the positive values between 0 and $\infty$ have been used, and accordingly $\Delta P$ has been multiplied by 2 . The sum of reflected sky radiances towards the zenith is therefore

$L_{\mathrm{r}, \mathrm{sky}}=\sum L(\theta)(2 \Delta P) \rho_{a, w}(\theta / 2)$,

where the sum is for all the $\theta$ intervals $0^{\circ}-1^{\circ}, 1^{\circ}-2^{\circ}, 2^{\circ}-3^{\circ}$, $\ldots 89^{\circ}-90^{\circ}$, and where $\rho_{a, w}(\theta / 2)$ is the Fresnel reflection at 
the air-water interface for an angle of incidence equal to $\theta / 2$. The problem of polarization will be discussed in Sect. 3.1.

As a test it has been confirmed that

$\sum(2 \Delta P)=1$.

Since we are studying the radiance reflected towards the zenith, the azimuth angle between this direction and the position of the sun is undetermined. The tabulated values of the irradiance $E_{\text {sun0 }}$ of the direct solar rays on a plane normal to the rays (Høkedal and Aas, 1998) have accordingly been converted to equivalent azimuthal mean values of solar radiance. The angle of the solar diameter is approximately $0.5^{\circ}$, but since our calculations apply $\Delta \theta=1^{\circ}$, it is practical to distribute the solar radiation within the solid angle $2 \pi \sin \left(\theta_{s}\right)$ $\Delta \theta=0.10966 \sin \left(\theta_{s}\right)$, where $\theta_{s}$ is the solar zenith angle. The resulting equivalent solar radiance becomes

$L_{\text {sun }}\left(\theta_{s}\right)=E_{\text {sun } 0} /\left(0.1097 \sin \theta_{s}\right)$.

The average contribution from the sun glitter can then be described by an expression similar to Eq. (19):

$L_{\mathrm{r}, \text { sun }}=L_{\mathrm{sun}}\left(\theta_{s}\right)(2 \Delta P) \rho_{a, w}\left(\theta_{s} / 2\right)$.

It should be emphasized that the values of the probability distribution function $P$ used in Eq. (19) and (22) is a simplified form of the Cox-Munk model, and that the average relationship between wind speed and mean square slopes, Eq. (9), is based on observations from the Hawaiian area of the Pacific Ocean. The corresponding relationship in Nordic coastal areas may be different due to differences in wind duration, fetch and boundary layer stabilities in the sea and atmosphere. The coastline and bottom topography may also influence the sea state. Thus the results discussed here are only meant as a first approximation to the real local conditions.

\subsection{Calculation of radiance reflected from the foam-covered part of the surface}

It can easily be observed that the fraction $F$ of the surface that is covered by foam and whitecaps from breaking waves increases with increasing wind speed $W$. The relationship between $F$ and $W$ has been discussed in several papers, e.g. Monahan (1971), Monahan and O'Muircheartaigh (1980, 1981, 1986), and Wu (1979). Monahan and O'Muircheartaigh (1980) obtained by the method of least squares the power-law

$F=2.95 \times 10^{-6} W^{3.52}$,

where $W$ is in units of $\mathrm{ms}^{-1}$. The equation yields $F=$ 0.0098 for $W=10 \mathrm{~m} \mathrm{~s}^{-1}$. Thus less than $1 \%$ of the surface is covered by foam at wind speeds up to $10 \mathrm{~m} \mathrm{~s}^{-1}$. In a later work Monahan and O'Muircheartaigh (1986) estimated $F$ as a function of the temperature difference $\Delta T=T_{\text {air }}-T_{\text {sea }}$. Using monthly mean values of $\Delta T$ for the Færder Lighthouse at the northern border of the Skagerrak, the values of
$F$ become smaller than those obtained from Eq. (23). In the present study Eq. (23) is applied due to its simplicity.

Lauscher (1955) mentioned that foam of a sufficient thickness would reflect 50-80\%. Whitlock et al. (1982) recorded the irradiance reflectance $\rho_{f 0}$ of foam in a laboratory tank and found that a reasonable constant value for the reflectance in the visible part of the spectrum at wavelengths of $440 \mathrm{~nm}$ and longer was $\rho_{f 0}=0.5 \pm 0.1$. Also Frouin et al. (1996) obtained values of $\rho_{f 0}$ within the same range for breaking waves in the surf zone at La Jolla, California. In the open sea the foam reflectance seems to be smaller than in these investigations. Based on several series of photos from a research platform in the German Bight Koepke (1984) found that the time-averaged reflectance of the foam was $\rho_{f 0}=0.22 \pm 0.11$ for wind speeds up to $10 \mathrm{~m} \mathrm{~s}^{-1}$.

It is well established that the reflection from foam in the near infrared is smaller than in the visible part (Whitlock et al., 1982; Frouin et al., 1996; Moore et al., 1998, 2000; Nicolas et al., 2001; Kokhanovsky, 2004). The spectral variation in the visible part of the spectrum may depend on the thickness of the foam, according to Moore et al. (1998), who found that average reflectances at 410, 440, 510, 550, 670 and $860 \mathrm{~nm}$ were in the ranges $0.81-0.86,1,0.99-1.01$, $0.98-0.99,0.73-0.87,0.38-0.59$, respectively, when normalized at $440 \mathrm{~nm}$. However, in a later work by the same authors (Moore et al., 2000) the reflectances seem to be constant from 410 to $670 \mathrm{~nm}$, and then smaller at $860 \mathrm{~nm}$. In this paper $\rho_{f 0}$ has been given the constant value 0.22 for the spectral range $405-650 \mathrm{~nm}$. Visual observations of the foam in the Oslofjord-Skagerrak area, with its yellow substancerich Case 2 waters, have indicated no spectral dependency.

Neglecting any bi-directional effects and assuming that the foam acts as a Lambertian emitter, $\rho_{f 0}$ can be related to the upward reflected radiance from the patch or streak of foam, $L_{\mathrm{r} \text {,foam, } 0}$, and the total downward irradiance in air, $E_{\mathrm{tot}}$, by

$\rho_{f 0}=\pi L_{\mathrm{r}, \text { foam }, 0} / E_{\text {tot }}$.

The foam-reflected radiance can then be written

$L_{\mathrm{r}, \text { foam }, 0}=\frac{\rho_{f 0}}{\pi} E_{\mathrm{tot}}$.

This radiance has to be weighted by the fractional area $F$ of the foam in order to obtain the average contribution $L_{r}$,foam to the total reflected radiance at the surface:

$L_{\mathrm{r}, \text { foam }}=F L_{\mathrm{r}, \text { foam }, 0}=F \frac{\rho_{f 0}}{\pi} E_{\mathrm{tot}}$.

If $F$ can be expressed by Eq. (23) and $\rho_{f 0}=0.22$, then Eq. (26) can be written

$L_{\mathrm{r}, \text { foam }}=F \frac{\rho_{f 0}}{\pi} E_{\mathrm{tot}}=\left(2.07 \times 10^{-7} W^{3.52}\right) E_{\mathrm{tot}}$.

Moore et al. (2000) used a radiometric system, deployed from a ship, in equatorial waters of the Pacific Ocean. Winds speeds were in the range from 9 to $12 \mathrm{~m} \mathrm{~s}^{-1}$, and the data were collected during overcast conditions to avoid sun glints. 
Their augmented reflectance due to whitecaps and foam, $3.4 \times 10^{-6} W^{2.55}$, is close to the product $F \rho_{f 0}=0.65 \times$ $10^{-6} W^{3.52}$ of Eq. (27) up to a wind speed of $7 \mathrm{~m} \mathrm{~s}^{-1}$, but at stronger winds their reflectances are smaller.

\subsection{Total reflected radiance at the surface}

The total radiance reflected towards zenith at the surface of the sea can be written

$L_{\mathrm{r}}=(1-F)\left(L_{\mathrm{r}, \text { sky }}+L_{\mathrm{r}, \text { sun }}\right)+F L_{\mathrm{r}, \text { foam }, 0}$,

where the radiances have been weighted by their respective fractions of surface area. However, since $F \leq 1 \%$ according to Eq. (23) when $W \leq 10 \mathrm{~m} \mathrm{~s}^{-1}$, Eq. (28) may without any significant loss of accuracy be simplified to

$L_{\mathrm{r}}=L_{\mathrm{r}, \text { sky }}+L_{\mathrm{r}, \text { sun }}+F L_{\mathrm{r}, \text { foam }, 0}=L_{\mathrm{r}, \text { sky }}+L_{\mathrm{r}, \text { sun }}+L_{\mathrm{r}, \text { foam }}$.

$L_{\mathrm{r} \text {,foam }}$ is directly related to $E_{\mathrm{tot}}$ by Eq. (27), and $L_{\mathrm{r} \text {,sun }}$ is related to $E_{\text {sun }}$ by Eqs. (21-22). $E_{\text {tot }}$ can be separated into the contributions from the diffuse sky irradiance $E_{\text {sky }}$ and the direct solar irradiance $E_{\text {sun }}$

$E_{\mathrm{tot}}=E_{\mathrm{sky}}+E_{\mathrm{sun}}$.

$L_{\mathrm{r} \text {,sky }}$ and $E_{\mathrm{sky}}$ are both functions of the azimuthal mean values $L(\theta)$ of the sky radiance; $L_{\mathrm{r}, \text { sky }}$ by Eq. (19), and $E_{\text {sky }}$ by

$E_{\mathrm{sky}}=2 \pi \int_{0}^{\pi / 2} L(\theta) \sin (\theta) \cos (\theta) d \theta=\pi \int_{0}^{\pi / 2} L(\theta) \sin (2 \theta) d \theta$.

All three terms of the reflected radiance $L_{\mathrm{r}}$ can then by calculated, provided $L(\theta), E_{\text {sun }, 0}$ or $E_{\text {sun }}$, and $W$ have been recorded.

\subsection{Calculation of water-leaving radiance}

From the definition of radiance and Snell's Law it can readily be obtained that an upward radiance just beneath the surface, $L_{\mathrm{w}}^{0-}$, produces a contribution $\Delta L_{\mathrm{w}}$ to the water-leaving radiance by

$\Delta L_{w}=L_{\mathrm{w}}^{0-} \frac{\tau}{n^{2}}$,

where $\tau$ is the transmittance of radiance through the waterair interface. The azimuthal mean value of $L_{\mathrm{w}}^{0-}$ from the nadir angle $\theta_{\mathrm{w}}$ is denoted $L_{\mathrm{w}}^{0-}\left(\theta_{\mathrm{w}}\right)$. Assume that we know this mean value for all the $\theta_{\mathrm{w}}$ intervals $0^{\circ}-1^{\circ}, 1^{\circ}-2^{\circ}, 2^{\circ}-$ $3^{\circ}, \ldots 89^{\circ}-90^{\circ}$. This series of $\theta_{\mathrm{w}}$ intervals corresponds to a series of $\beta$ intervals determined by Eqs. (16-17). Note that although $\Delta \theta_{\mathrm{w}}$ is constant, $\Delta \beta$ decreases with increasing $\theta_{\mathrm{w}}$ due to Snell's Law. The new series of $\beta$ intervals produces a series of $m$ by Eq. (1) and for a fixed wind speed a series of $s$ intervals by Eq. (11). For each sinterval there is a probability $\Delta P$ for $s$ being in this interval (Eq. 18).
The total water-leaving radiance is the sum of the contributions from all upward radiances in water, transmitted through the surface and refracted towards zenith:

$L_{\mathrm{w}}=\sum L_{\mathrm{w}}^{0-}\left(\theta_{\mathrm{w}}\right)(2 \Delta P) \frac{\tau(j)}{n^{2}}$.

The sum is for all the $\theta_{\mathrm{w}}$ intervals $0^{\circ}-1^{\circ}, 1^{\circ}-2^{\circ}, 2^{\circ}-3^{\circ}$, $\ldots 89^{\circ}-90^{\circ}$, and $\tau(j)$ is the Fresnel transmittance at the waterair interface for an angle of incidence equal to $j$.

\subsection{Observations of radiance and irradiance from sky and sun}

A total of 52 data sets of angular distributions of sky radiance and direct solar irradiances, representing 9 different days with a clear sky, were collected in Oslo by Høkedal and Aas (1998) at the wavelengths $405,450,520,550$ and $650 \mathrm{~nm}$, for solar zenith angles in the range $37^{\circ}-76^{\circ}$. The recordings were made manually by means of a tripod and a rotating Gershun tube provided with interference filters, often located on the roof of the high department building at the University of Oslo. The Gershun tube was of local construction (Aas, 1993), and its opening half-angle was $5.5^{\circ}$ in order to ensure stable signals. Details of the calibration have been presented elsewhere (Aas, 1993). Measurements were taken over the upper hemisphere in steps of $\Delta \theta=15^{\circ}\left(\right.$ range $\left.0^{\circ}-75^{\circ}\right)$ and $\Delta \alpha=24-36^{\circ}$ (range $0^{\circ}-180^{\circ}$ ). The time required for a complete recording with one filter was $15-20 \mathrm{~min}$. During that time the solar zenith angle $\theta_{s}$ would have changed by $0^{\circ}$ at noon, and $3^{\circ}$ in the afternoon, implying that the atmospheric conditions could be regarded as practically constant for our purposes. A full spectral series took $80-90 \mathrm{~min}$, corresponding to $\Delta \theta_{s}=7^{\circ}-15^{\circ}$. The radiance $L(\theta, \alpha)$ and the solar irradiance $E_{\text {sun }}$ were recorded directly by the Gershun tube, while $E_{\text {sky }}$ was obtained by integration of $L(\theta, \alpha)$ (Eq. 31), and $E_{\text {tot }}$ was then found by using Eq. (30). An earlier analysis of the results has been presented by Aas and Høkedal (1999).

\subsection{Observations of sub-surface radiance and irradiance}

During the Nordic Cruise to the Mediterranean in 1971 an extensive set of radiance and polarization data was collected onboard the R/V Helland-Hansen by Lundgren with an instrument constructed by the same person (Lundgren, 1971). The radiance sensor had an opening half-angle of $0.7^{\circ}$, and the wavelengths were in the range 405-502 $\mathrm{nm}$. The subsurface radiance field was recorded in steps of $\Delta \theta_{\mathrm{w}}=5^{\circ}-30^{\circ}$, while all azimuth angles were recorded in one continuous sweep of the instrument. The data were stored as graphs on paper rolls from printers. Through the years the recordings were read off and tabulated (Lundgren 1971; Aas et al., 1997), and analyses were made (Højerslev and Aas, 1997; Aas and Højerslev, 1999; Adams et al., 2002 ). 
Observations of radiance from nadir and upward and downward irradiance in the Oslofjord and Skagerrak, together with downward irradiance above the surface, have been collected by the Norwegian Institute for Water Research and the University of Oslo during several co-projects. The measurements have usually been taken onboard the R/V Trygve Braarud and G. M. Dannevig with the PRR-600 from Biospherical Instruments, San Diego, California, and the deck reference has been the PRR-601. The wavelengths are $412,443,490,510,555$ and $665 \mathrm{~nm}$, and the opening halfangle of the radiance sensor is $10^{\circ}$ in water. The immersion coefficients provided by the manufacturer have been applied, and the self-shading effect (Gordon and Ding, 1992; Zibordi and Ferrari, 1995; Aas and Korsbø, 1997) has been accounted for. The upward radiance just beneath the surface, $L_{\mathrm{w}}^{0-}$, was obtained by upward extrapolation from a depth of $0.5-1 \mathrm{~m}$. This method requires that the vertical attenuation coefficient of the radiance is approximately constant within the upper meters of the surface layer. Factors like wave action, bubbles and accumulation of phytoplankton and detritus close to the surface may destroy the assumed constancy and thus influence the accuracy of the estimated $L_{\mathrm{w}}^{0-}$, but as explained in another work (Aas et al., 2009), no clear signs of such influences have ever been found in the vertical profiles.

\section{Results and discussion}

\section{1 $L_{\mathrm{r}, \text { sky }} L_{\mathrm{r} \text {,sun }}$ and $L_{\mathrm{r}, \text { foam }}$}

The observations of sky radiance made by Høkedal and Aas (1998) did not include the degree of polarization, except on two dates, and the reflectances were therefore calculated as if the radiance from the sky was unpolarized. This is certainly not correct. Their analyses showed that by neglecting the polarization the relative error of the reflected radiance for a flat sea might range from $-39 \%$ to $+14 \%$. A negative error means that the calculated reflectance is less than the correct value. The reflected sky irradiance, based on radiances from the whole hemisphere, was underestimated by $2 \%$ to $5 \%$. In the present analysis azimuthal mean values of the radiances are used, and a further analysis of the measurements shows that the relative errors of the corresponding reflectances are in the range from $-10 \%$ to $+1 \%$ for radiances incident from zenith angles between $15^{\circ}$ and $75^{\circ}$. If only zenith angles up to $45^{\circ}$ are taken into account, then the range of the relative errors will be reduced, extending from $-4 \%$ to $+1 \%$ with a mean value of $-2 \%$. The slope distribution function $\Delta P$ (Eq. 18) gives more weight to the smaller values of $\theta$ than to the larger ones, as demonstrated by Fig. 5, and the polarization errors are smaller for the smaller values of $\theta$. Figure 3, as already mentioned, shows that $90 \%$ of the contribution to the reflected radiance towards zenith comes from zenith angles less than $40^{\circ}$ for wind speeds up to $10 \mathrm{~m} \mathrm{~s}^{-1}$. Thus it seems reasonable to assume that on average our cal-

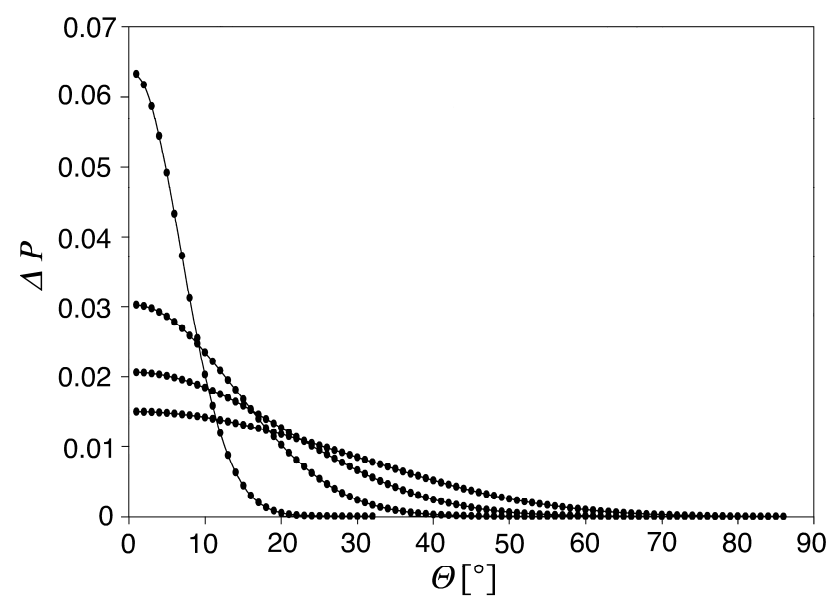

Fig. 5. The probability distribution $\Delta P$ as a function of the corresponding zenith angle $\theta$ in air. The curves represent from top to bottom in the left part of the graph the wind speeds $0,2,5$ and $10 \mathrm{~m} \mathrm{~s}^{-1}$.

culated reflectances may be underestimated by $2 \%$ due to the neglected polarization.

Kattawar and Adams (1990) used Monte Carlo simulations to study the effect of polarization on reflected and transmitted radiance at the surface of the sea. They found that errors up to $30 \%$ might occur in the radiances if the polarization was neglected. On the other hand, their results also showed that a positive error for one azimuth direction tended to be partly compensated for by a negative error for the opposite direction. The resulting errors of the azimuthal mean values of the radiances can be read off as ranging from 0 to $9 \%$. Kattawar and Adams also found that the error of neglecting polarization effects in the calculation of irradiance reflected upwards at the surface was $\leq 2 \%$. Consequently their model results support the field results of Høkedal and Aas.

Two factors influencing the amount of reflected light, especially for directions of incidence close to the horizon, are the processes of shadowing and multiple reflections. A facet of the surface may experience shadowing from other parts of the wave and from other waves, thus reducing the amount of reflected light. The process of multiple reflections, on the other hand, increases the reflectance for some directions. The influence of these effects on the upward-reflected light from the sea surface has been discussed by Preisendorfer and Mobley (1986) and Gordon and Wang (1992a, b). In the present paper the effects have not been taken into account, since more than $90 \%$ of the contributions to the zenith-reflected light comes from zenith angles less than $40^{\circ}$ for wind speeds up to $10 \mathrm{~m} \mathrm{~s}^{-1}$, that is from directions closer to the zenith than to the horizon.

The 52 data sets described in Sect. 2.6 were used to calculate $L_{\mathrm{r}, \mathrm{sky}}, L_{r \text {,sun }}$ and $L_{\mathrm{r} \text {,foam }}$, as expressed by Eqs. (19, 22 ) and (27), and $L_{\mathrm{r}}$ was then obtained by adding the three quantities (Eq. 29). The Fresnel reflectances were calculated 


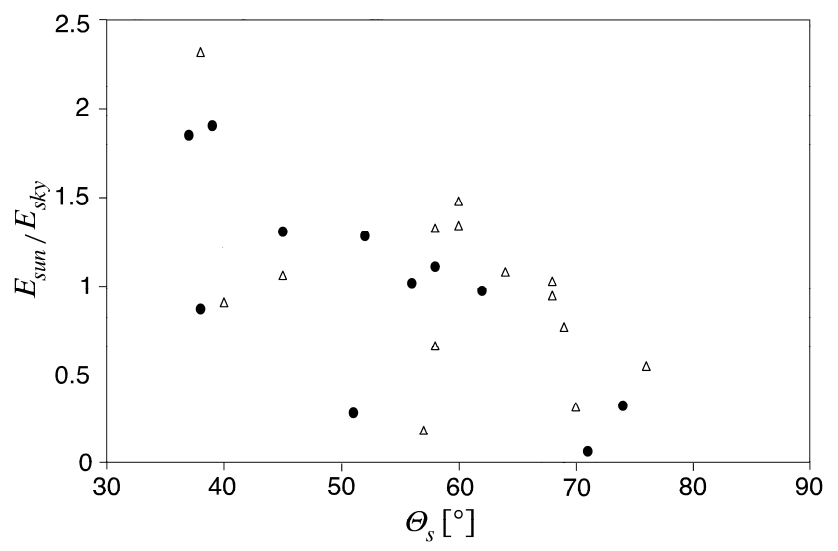

Fig. 6. The ratio $E_{\text {sun }} / E_{\text {sky }}$ as a function of the solar zenith angle $\theta_{s}$. The filled circles and open triangles represent 405 and $650 \mathrm{~nm}$, respectively. The ratios are normalized against their mean values at these wavelengths.

for a refractive index of 1.340 , corresponding to the average conditions of salinity, temperature and wavelength being approximately $30,15^{\circ} \mathrm{C}$ and $550 \mathrm{~nm}$, respectively. The variation of the reflectances with regard to these three parameters is insignificant compared to the mentioned uncertainty introduced by the polarization.

\subsection{The ratio $L_{\mathrm{r}} / L\left(0^{\circ}\right)$}

The obvious method (e.g. Austin, 1974) to estimate $L_{\mathrm{r}}$ for a flat sea and a certain direction of observation $180^{\circ}-\theta$ is to record the sky radiance in the same plane of incidence but from the zenith angle $\theta$, and multiply the radiance by the corresponding Fresnel reflectance $\rho_{a, w}$. In our case, where $\theta$ is $0^{\circ}$, the radiance reflected at the surface towards the zenith could be written

$L_{\mathrm{r}}=L\left(0^{\circ}\right) \rho_{a, w}\left(0^{\circ}\right)$,

The ratio $L_{\mathrm{r}} / L\left(0^{\circ}\right)$ is

$L_{\mathrm{r}} / L\left(0^{\circ}\right)=\rho_{a, w}\left(0^{\circ}\right)=0.0211$,

where $\rho_{a, w}\left(0^{\circ}\right)=0.0211$ is the value of the Fresnel reflectance used in our calculations for a ray of normal incidence. However, for a surface roughened by the wind the reflectance $\rho_{a, w}$ will depend on the wind speed and the solar zenith angle, and because our case with zenith-reflected radiance is outside the recommended range of viewing angles (references in Sect. 1), we must expect significant contributions from direct solar glitter.

The results for the ratio $L_{\mathrm{r}} / L\left(0^{\circ}\right)$, calculated by Eqs. (19, $22,27,29)$, and presented in Table 1 , show that the flat-sea estimate of $L_{\mathrm{r}} / L\left(0^{\circ}\right)$ expressed by Eq. (35) works well for a zero wind speed, since the ratio is within the range $0.0201-$ 0.0220 , with a mean value of 0.0215 . The small deviations from a constant value are due to the mean square slope which is not zero even in the absence of wind, but 0.003 according to Eq. (9). When the wind speed $W$ increases up to $10 \mathrm{~m} \mathrm{~s}^{-1}$, the mean value of the ratio increases from 0.0215 to 0.0784 , which is a factor 3.7 greater than the value 0.0211 suggested by Eq. (35). In one case the ratio becomes 0.388 , which is greater than 0.0211 by a factor of 18 . The mean value of $\theta_{s}$ in Table 1 is $58^{\circ}$, and it is noteworthy that the simulations of Mobley (1999, Fig. 6) for $W=10 \mathrm{~m} \mathrm{~s}^{-1}$ and a nadir viewing angle seem to produce a mean value of the ratio of approximately 0.03 for the same solar zenith angle. This is less than half of the present result. Mobley points out the importance of the input from the sky radiance distribution, and it is possible that the difference in results may be due to different inputs.

If we separate $L_{\mathrm{r}} / L\left(0^{\circ}\right)$ into the components $L_{\mathrm{r}, \mathrm{sky}} / L\left(0^{\circ}\right)$, $L_{\text {r, sun }} / L\left(0^{\circ}\right)$ and $L_{\text {r,foam }} / L\left(0^{\circ}\right)$, we find that $L_{\text {r, sky }} / L\left(0^{\circ}\right)$ only ranges from 0.020 to 0.029 (Table 1 ). It also becomes clear that $L_{\mathrm{r} \text {, sun }} / L\left(0^{\circ}\right)$ represents the smallest and greatest normalized reflectances toward the zenith (Table 1), ranging from 0 to 0.31 . An interesting result is that the ratio $L_{\mathrm{r}, \operatorname{sun}} / L\left(0^{\circ}\right)$ is much smaller than $L_{\mathrm{r}, \mathrm{sky}} / L\left(0^{\circ}\right)$ for certain values of $\theta_{s}$, as listed by Table 2 . In these cases the contribution from sun glitter to the radiance directed towards the zenith can be neglected. Table 1 shows that the radiance reflected from foam can be neglected at a wind speed of $W=5 \mathrm{~m} \mathrm{~s}^{-1}$, but contributes significantly to $L_{\mathrm{r}}(24 \%$ on an average) when $W=10 \mathrm{~m} \mathrm{~s}^{-1}$. A closer examination of the data reveals that $L_{\text {r,foam }} / L\left(0^{\circ}\right)$ reaches the value of 0.001 at wind speeds between 5 and $7 \mathrm{~m} \mathrm{~s}^{-1}$, implying that $L_{\mathrm{r} \text {,foam }}$ should be taken into account whenever the wind speed is greater than $5 \mathrm{~m} \mathrm{~s}^{-1}$. This is consistent with the sea state described by the Beaufort wind scale (Sect. 1). The ratio $L_{\mathrm{r} \text {,foam }} / L_{\mathrm{r} \text {, sky }}$ tends to decrease with increasing $\theta_{s}$.

The results of Table 2 indicate that in the Northern Skagerrak, where the solar zenith angles $\theta_{s} \geq 37^{\circ}$, Eq. (35) is only valid when the wind speed is low $\left(W<2 \mathrm{~m} \mathrm{~s}^{-1}\right)$. At higher wind speeds ( $W>2 \mathrm{~m} \mathrm{~s}^{-1}$ ), Eq. (35) is valid for a restricted range of $\theta_{s}$, where the lower limit of the range increases with increasing wind speed. When the wind speed is $10 \mathrm{~m} \mathrm{~s}^{-1}, \theta_{s}$ should be approximately $80^{\circ}$ or greater in order to avoid sun glitter in the zenith direction. Table 2 also implies that in the Polar regions, where the sun is low, solar glitter is probably not a problem at moderate wind speeds when the direction of observation is close to the nadir.

Rather than using the constant Fresnel reflectance 0.0211 to represent the ratio $L_{\mathrm{r}} / L\left(0^{\circ}\right)$ in Eq. (35), we could approximate the ratios $L_{\mathrm{r}, \mathrm{sky}} / L\left(0^{\circ}\right), L_{\mathrm{r}, \text { sun }} / L\left(0^{\circ}\right)$ and $L_{\mathrm{r} \text {, foam }} / L\left(0^{\circ}\right)$ by their respective bulk mean spectral values for all solar zenith angles in the present data set, and test if that improved the results. Table 3 shows that the standard deviation from the mean value of $L_{\mathrm{r}, \mathrm{sky}} / L\left(0^{\circ}\right)$ is now less than 0.002 at wavelengths $405,450,520,550$ and $650 \mathrm{~nm}$, and for wind speeds up to $10 \mathrm{~m} \mathrm{~s}^{-1}$. The maximum deviation of $L_{\mathrm{r}, \mathrm{sky}} / L\left(0^{\circ}\right)$ from the mean value in the obtained data set is less than 0.005 . Data for $L_{\mathrm{r} \text {, sun }} / L\left(0^{\circ}\right)$ where the values were 
Table 1. Statistical properties of radiance ratios. Deviations are from the mean value.

\begin{tabular}{lcccccccccccccc}
\hline & \multicolumn{1}{c}{$L_{\mathrm{r}} / L\left(0^{\circ}\right)$} & & \multicolumn{3}{c}{$L_{\mathrm{r}, \mathrm{sky}} / L\left(0^{\circ}\right)$} & \multicolumn{3}{c}{$L_{\mathrm{r}, \mathrm{sun}} / L\left(0^{\circ}\right)$} & \multicolumn{4}{c}{$L_{\mathrm{r}, \text { foam }} / L\left(0^{\circ}\right)$} \\
\hline$W\left[\mathrm{~m} \mathrm{~s}^{-1}\right]$ & 0 & 5 & 10 & 0 & 5 & 10 & 0 & 5 & 10 & 0 & 5 & 10 \\
Mean value & 0.0215 & 0.0348 & 0.0784 & 0.0215 & 0.0237 & 0.0260 & 0 & 0.0110 & 0.0333 & 0 & 0.0002 & 0.0191 \\
Minimum value & 0.0201 & 0.0232 & 0.0298 & 0.0201 & 0.0198 & 0.0206 & 0 & 0 & 0.0002 & 0 & 0.0000 & 0.0040 \\
Maximum value & 0.0220 & 0.1901 & 0.3884 & 0.0220 & 0.0253 & 0.0292 & 0 & 0.1672 & 0.3145 & 0 & 0.0005 & 0.0531 \\
Standard deviation & 0.0003 & 0.0261 & 0.0575 & 0.0003 & 0.0010 & 0.0018 & 0 & 0.0264 & 0.0494 & 0 & 0.0001 & 0.0137 \\
Max. deviation & 0.0014 & 0.1553 & 0.3100 & 0.0014 & 0.0039 & 0.0055 & 0 & 0.1563 & 0.2813 & 0 & 0.0003 & 0.0339 \\
\hline
\end{tabular}

Table 2. Ranges of $\theta_{S}$ where sun glitter can be neglected.

\begin{tabular}{lcc}
\hline$W\left[\mathrm{~m} \mathrm{~s}^{-1}\right]$ & $L_{\mathrm{r}, \text { sun }} / L\left(0^{\circ}\right)<0.002$ & $L_{\mathrm{r}, \mathrm{sun}} / L\left(0^{\circ}\right)<0.001$ \\
\cline { 2 - 3 } & $\theta_{s}$ & $\theta_{s}$ \\
\hline 0 & $\geq 37^{\circ}$ & $\geq 37^{\circ}$ \\
1 & $\geq 37^{\circ}$ & $\geq 37^{\circ}$ \\
2 & $\geq 47^{\circ}$ & $\geq 50^{\circ}$ \\
3 & $\geq 55^{\circ}$ & $\geq 57^{\circ}$ \\
5 & $\geq 65^{\circ}$ & $\geq 68^{\circ}$ \\
10 & $\geq 78^{\circ}$ & \\
\hline
\end{tabular}

much smaller than $L_{\mathrm{r}, \mathrm{sky}} / L\left(0^{\circ}\right)$, were not used in the statistical calculations of $L_{\mathrm{r} \text {,sun }} / L\left(0^{\circ}\right)$. Unfortunately the standard and maximum deviations for this ratio are still too great to be acceptable, amounting to 0.24 in the red part of the spectrum for $W=10 \mathrm{~m} \mathrm{~s}^{-1}$. The deviations of $L_{\mathrm{r}, \text { foam }} / L\left(0^{\circ}\right)$ from the mean values at the different wavelengths are of the same order of magnitude as $L_{\mathrm{r}, \mathrm{sky}} / L\left(0^{\circ}\right)$ when $W=10 \mathrm{~m} \mathrm{~s}^{-1}$. Accordingly the use of the bulk mean value to estimate the ratios $L_{\mathrm{r} \text {,sun }} / L\left(0^{\circ}\right)$ and $L_{\mathrm{r}, \text { foam }} / L\left(0^{\circ}\right)$ is not a satisfactory method.

An additional experiment has been conducted by approximating the three ratios $L_{\mathrm{r} \text {,sky }} / L\left(0^{\circ}\right), L_{\mathrm{r} \text {,sun }} / L\left(0^{\circ}\right)$ and $L_{\mathrm{r} \text {,foam }} / L\left(0^{\circ}\right)$ by best-fit second order polynomials on the form $A+B_{1} \theta_{s}+B_{2} \theta_{s}^{2}$, where $A, B_{1}$ and $B_{2}$ are constants, for the different wavelengths and wind speeds. The errors are then reduced, but they are still too large for $L_{\mathrm{r}, \text { sun }} / L\left(0^{\circ}\right)$ and $L_{\mathrm{r} \text {,foam }} / L\left(0^{\circ}\right)$. At winds of 5 and $10 \mathrm{~m} \mathrm{~s}^{-1}$ the errors of $L_{\mathrm{r}, \mathrm{sun}} / L\left(0^{\circ}\right)$ amounted to 0.025 and 0.047 , respectively, and at $10 \mathrm{~m} \mathrm{~s}^{-1}$ the errors of $L_{\mathrm{r}, \text { foam }} / L\left(0^{\circ}\right)$ could reach 0.013 . These errors are of the same order of magnitude as the mean values of $L_{\mathrm{r}, \mathrm{sky}} / L\left(0^{\circ}\right), 0.022-0.026$, as shown by Table 1 .

The ratio $L_{\mathrm{r}, \mathrm{sky}} / L\left(0^{\circ}\right)$ can be described with satisfactory accuracy by the mean values of Tables 1 and 3 , and by the second order polynomials of $\theta_{s}$ in Table 5. An additional useful property of the ratio is that if the value of $L_{\mathrm{r}, \mathrm{sky}} / L\left(0^{\circ}\right)$ is known at one wavelength, then this value can be applied to the other wavelengths as well. For instance, if the ratio is known at $405 \mathrm{~nm}$, then the assumption that the ratio is the same at the other wavelengths, leads to relative RMS errors of $1-4-7 \%$ for the wind speeds $0-5-10 \mathrm{~m} \mathrm{~s}^{-1}$, respectively.
These errors are rather small compared to other errors connected with field measurements.

The "dark pixel" assumption is that in the near infrared the total radiance from the sea will mainly consist of sky and solar radiance reflected at the surface. If our zenith-reflected radiance contains no sun glints, then the ratio $L_{\mathrm{r}, \mathrm{sky}} / L\left(0^{\circ}\right)$ can be assumed constant with wavelength and equal to the recorded value of $L_{\mathrm{r}} / L\left(0^{\circ}\right)$ in the near infrared (Morel 1980).

The different tests discussed here demonstrate that while the reflected sky radiance $L_{\mathrm{r} \text {,sky }}$ is normalized in a useful way by the sky radiance $L\left(0^{\circ}\right)$, this normalization does not work

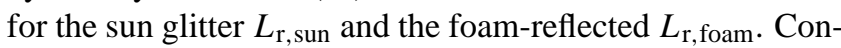
sequently better normalizing quantities or reference inputs should be found for these two radiances. It was pointed out in Sect. 2.4 how $L_{\mathrm{r} \text {,foam }}$ is related to $E_{\mathrm{tot}}$, and $L_{\mathrm{r} \text {,sun }}$ to $E_{\text {sun }}$. It was also mentioned that $L_{\mathrm{r} \text {,sky }}$ is indirectly related to $E_{\text {sky }}$, since both quantities are functions of the sky radiance $L(\theta)$. A common normalizing quantity is unrealistic because there is no constant ratio between $E_{\text {sky }}$ and $E_{\text {sun }}$ at a given wavelength, wind speed or solar zenith angel. The ratio varies in an unpredictable way due to different optical conditions of the atmosphere, as displayed by Fig. 6 . Here $E_{\text {sun }} / E_{\text {sky }}$ varies by an order of magnitude, both in the violet $(405 \mathrm{~nm})$ and red $(650 \mathrm{~nm})$ parts of the spectrum. During the measurements of the two irradiances the solar zenith angle only varied by $0^{\circ}-$ $3^{\circ}$, and the varying values of $E_{\text {sun }} / E_{\text {sky }}$ shown by Fig. 6 must accordingly be due to variation of the atmospheric conditions from one day to another.

\subsection{The ratios $L_{\mathrm{r}, \text { foam } / \mathrm{E}_{\text {tot }}}, L_{\mathrm{r} \text {,sun }} / E_{\mathrm{sun}}$ and $L_{\mathrm{r}, \mathrm{sky}} / E_{\mathrm{sky}}$}

At a given wind speed $L_{\mathrm{r} \text {,foam }}$ is a linear function of $E_{\mathrm{tot}}$, as shown by Eq. (27). The constant of proportionality is independent of the wavelength and solar angle, and depends only on the wind speed by a power-law.

The sun glitter $L_{\mathrm{r}, \text { sun }}$ is related to $E_{\text {sun }}$ by Eqs. (21-22), and both the wind speed and the solar angle influence its magnitude by means of the slope distribution function. The wavelength, however, has no practical influence, since the Fresnel reflectance of the surface is almost independent of wavelength. Accordingly $L_{\mathrm{r} \text {,sun }}$ has been normalized by $E_{\text {sun }}$, and the ratio $L_{\mathrm{r}, \text { sun }} / E_{\mathrm{sun}}$ has been approximated by 
Table 3. Statistical properties of radiance ratios at different wavelengths.

\begin{tabular}{|c|c|c|c|c|c|c|c|}
\hline \multirow{3}{*}{ Wavelength [nm] } & \multirow{3}{*}{$W\left[\mathrm{~m} \mathrm{~s}^{-1}\right]$} & \multirow{2}{*}{\multicolumn{3}{|c|}{$\begin{array}{c}L_{\mathrm{r}, \mathrm{sky}} / L\left(0^{\circ}\right) \\
\text { all } \theta_{s}\end{array}$}} & \multicolumn{2}{|c|}{$L_{\mathrm{r}, \operatorname{sun}} / L\left(0^{\circ}\right)$} & \multirow{3}{*}{$\begin{array}{c}L_{\mathrm{r}, \text { foam }} / L\left(0^{\circ}\right) \\
\text { all } \theta_{S} \\
10\end{array}$} \\
\hline & & & & & $\theta_{s}=37^{\circ}-60^{\circ}$ & $\theta_{s}=37^{\circ}-70^{\circ}$ & \\
\hline & & 0 & 5 & 10 & 5 & 10 & \\
\hline \multirow{3}{*}{405} & Mean value & 0.0213 & 0.0228 & 0.0243 & 0.0102 & 0.0216 & 0.0079 \\
\hline & Standard deviation & 0.0004 & 0.0011 & 0.0016 & 0.0119 & 0.0189 & 0.0024 \\
\hline & Max. deviation & 0.0012 & 0.0030 & 0.0037 & 0.0215 & 0.0350 & 0.0039 \\
\hline \multirow{3}{*}{450} & Mean value & 0.0215 & 0.0234 & 0.0254 & 0.0094 & 0.0215 & 0.0106 \\
\hline & Standard deviation & 0.0001 & 0.0005 & 0.0011 & 0.0124 & 0.0203 & 0.0038 \\
\hline & Max. deviation & 0.0002 & 0.0008 & 0.0021 & 0.0227 & 0.0459 & 0.0059 \\
\hline \multirow{3}{*}{520} & Mean value & 0.0215 & 0.0239 & 0.0262 & 0.0185 & 0.0419 & 0.0162 \\
\hline & Standard deviation & 0.0003 & 0.0006 & 0.0008 & 0.0293 & 0.0467 & 0.0071 \\
\hline & Max. deviation & 0.0007 & 0.0014 & 0.0013 & 0.0572 & 0.1005 & 0.0101 \\
\hline \multirow{3}{*}{550} & Mean value & 0.0216 & 0.0241 & 0.0270 & 0.0093 & 0.0306 & 0.0214 \\
\hline & Standard deviation & 0.0002 & 0.0008 & 0.0016 & 0.0121 & 0.0200 & 0.0101 \\
\hline & Max. deviation & 0.0005 & 0.0018 & 0.0038 & 0.0214 & 0.0305 & 0.0158 \\
\hline \multirow{3}{*}{650} & Mean value & 0.0216 & 0.0242 & 0.0272 & 0.0381 & 0.0730 & 0.0368 \\
\hline & Standard deviation & 0.0004 & 0.0012 & 0.0021 & 0.0592 & 0.0860 & 0.0138 \\
\hline & Max. deviation & 0.0009 & 0.0028 & 0.0050 & 0.1292 & 0.2415 & 0.0264 \\
\hline
\end{tabular}

Table 4. Relative RMS error of estimates in \% by two different normalizations.

\begin{tabular}{lcccc}
\hline Wavelength & \multicolumn{2}{c}{$L_{\mathrm{r}, \text { sun }} / L\left(0^{\circ}\right)$} & \multicolumn{2}{c}{$L_{\mathrm{r}, \text { sun }} / E_{\text {sun }}$} \\
{$[\mathrm{nm}]$} & $W=5 \mathrm{~m} \mathrm{~s}^{-1}$ & $W=10 \mathrm{~m} \mathrm{~s}^{-1}$ & $W=5 \mathrm{~m} \mathrm{~s}^{-1}$ & $W=10 \mathrm{~m} \mathrm{~s}^{-1}$ \\
\hline 405 & 70 & 69 & 12 & 8 \\
450 & 246 & 113 & 5 & 6 \\
520 & 148 & 140 & 12 & 4 \\
550 & 185 & 118 & 8 & 12 \\
650 & 387 & 128 & 21 & 4 \\
\hline
\end{tabular}

best-fit polynomials on the form $A+B_{1} \theta_{s}+B_{2} \theta_{s}^{2}$. We now find that the results are much more coherent than when the normalization was made by $L\left(0^{\circ}\right)$, as can clearly be seen by comparing the results in Table 4 . The striking fit between the polynomials and $L_{\mathrm{r} \text {,sun }} / E_{\mathrm{sun}}$ is shown by Fig. 7 . The polynomials for sun glitter reflected in the zenith direction at the wind speeds 3,5 and $10 \mathrm{~m} \mathrm{~s}^{-1}$ are presented in Table 5. An interesting and useful property of $L_{\mathrm{r} \text {,sun }} / E_{\text {sun }}$ is that its value is independent of wavelength, so that if its value is known at one wavelength, then the value is also known at all other wavelengths. This was pointed out by Zibordi et al. (2002), and the constancy is due to the very small spectral variation of the refractive index of sea water.

Similarly $L_{\mathrm{r} \text {, sky }}$ has been normalized by $E_{\text {sky }}$ in order to see whether the earlier results for $L_{\mathrm{r}, \mathrm{sky}} / L\left(0^{\circ}\right)$ can be improved. However, when $L_{\mathrm{r}, \mathrm{sky}} / E_{\mathrm{sky}}$ is approximated by bestfit polynomials of $\theta_{s}$, the overall errors of the resulting $L_{\mathrm{r}, \mathrm{sky}}$ are slightly greater than when $L_{\mathrm{r}, \mathrm{sky}} / L\left(0^{\circ}\right)$ was estimated in

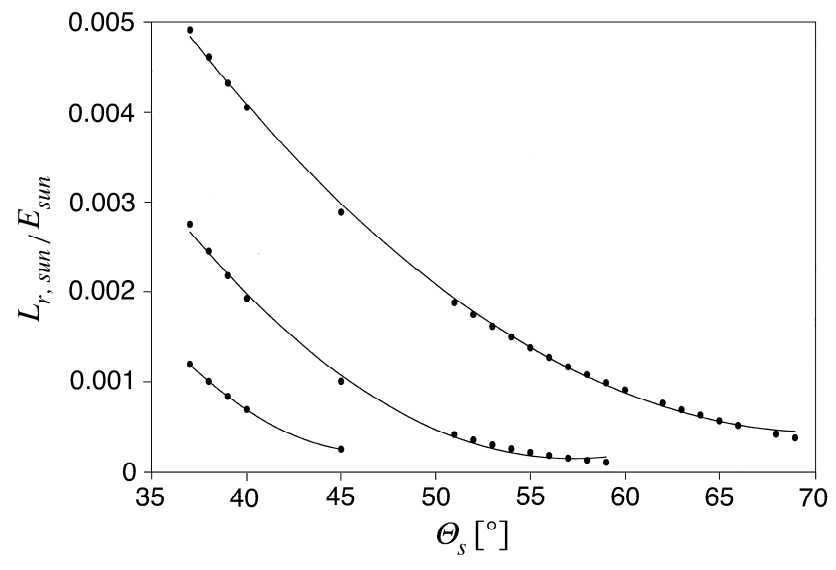

Fig. 7. The ratio $L_{\mathrm{r}, \operatorname{sun}} / E_{\mathrm{sun}}$ as a function of $\theta_{s}$, at the wavelengths $405,450,520,550$ and $650 \mathrm{~nm}$. Only ratios greater than 0.0001 are taken into account. The best-fit lines represent, from bottom to top, the wind speeds 3,5 and $10 \mathrm{~m} \mathrm{~s}^{-1}$, and their polynomials are presented in Table 5.

the same way. This is not surprising, since the sky radiances contributing to $L_{\mathrm{r} \text {,sky }}$ have directions and values closer to $L\left(0^{\circ}\right)$ than the radiances from the whole hemisphere contributing to $E_{\text {sky }}$. Consequently, if $L\left(0^{\circ}\right)$ has been observed, the overall best estimates of $L_{\mathrm{r} \text {, sky }}$ will be obtained by using the polynomials for $L_{\mathrm{r}, \mathrm{sky}} / L\left(0^{\circ}\right)$ (Table 5). 
Table 5. Polynomials for $L_{\mathrm{r}, \mathrm{sky}} / L\left(0^{\circ}\right), L_{\mathrm{r} \text {,sun }} / E_{\mathrm{sun}}$, and $E_{\mathrm{sky}} / L\left(0^{\circ}\right)$ on the form $A+B_{1} \theta_{s}+B_{2} \theta_{s}^{2}$, where $\theta_{s}$ is in units of degrees.

\begin{tabular}{|c|c|c|c|c|c|c|c|c|c|c|c|c|}
\hline & \multicolumn{9}{|c|}{$L_{\mathrm{r}, \mathrm{sky}} / L\left(0^{\circ}\right) \quad\left(\theta_{s}=37^{\circ}-76^{\circ}\right)$} & \multicolumn{3}{|c|}{$E_{\text {sky }} / L\left(0^{\circ}\right)\left(\theta_{s}=37^{\circ}-76^{\circ}\right)$} \\
\hline & \multicolumn{3}{|c|}{$W=0 \mathrm{~m} \mathrm{~s}^{-1}$} & \multicolumn{3}{|c|}{$W=5 \mathrm{~m} \mathrm{~s}^{-1}$} & \multicolumn{3}{|c|}{$W=10 \mathrm{~m} \mathrm{~s}^{-1}$} & & & \\
\hline Wavelength [nm] & $A\left[10^{-2}\right]$ & $B_{1}\left[10^{-6}\right]$ & $B_{2}\left[10^{-8}\right]$ & $A\left[10^{-2}\right]$ & $B_{1}\left[10^{-5}\right]$ & $B_{2}\left[10^{-8}\right]$ & $A\left[10^{-2}\right]$ & $B_{1}\left[10^{-4}\right]$ & $B_{2}\left[10^{-6}\right]$ & $A\left[10^{-1}\right]$ & $B_{1}\left[10^{-1}\right]$ & $B_{2}\left[10^{-3}\right]$ \\
\hline 405 & 2.08 & 5.61 & 5.45 & 2.08 & 3.36 & 6.85 & 1.72 & 1.93 & -1.05 & -8.86 & 1.65 & -1.03 \\
\hline 450 & 2.13 & -3.63 & 9.57 & 2.03 & 7.57 & -36.3 & 1.43 & 3.19 & -2.12 & -42.0 & 2.86 & -1.95 \\
\hline 520 & 2.23 & -17.9 & 6.41 & 2.55 & -3.81 & 15.6 & 2.06 & 1.86 & -1.47 & -30.9 & 2.66 & -1.80 \\
\hline 550 & 1.86 & 91.4 & -67.7 & 1.43 & 29.3 & -212 & 3.71 & -3.45 & 2.98 & -74.9 & 3.88 & -2.44 \\
\hline \multirow[t]{3}{*}{650} & 1.57 & 192 & -150 & 0.879 & 50.0 & -390 & 0.125 & 8.09 & -6.01 & -64.4 & 3.54 & -2.04 \\
\hline & \multicolumn{9}{|c|}{$L_{\mathrm{r}, \text { sun }} / E_{\mathrm{sun}}$} & & & \\
\hline & \multicolumn{3}{|c|}{$W=3 \mathrm{~m} \mathrm{~s}^{-1}\left(\theta_{s}=37^{\circ}-50^{\circ}\right)$} & \multicolumn{3}{|c|}{$W=5 \mathrm{~m} \mathrm{~s}^{-1}\left(\theta_{s}=37^{\circ}-60^{\circ}\right)$} & \multicolumn{3}{|c|}{$W=10 \mathrm{~m} \mathrm{~s}^{-1}\left(\theta_{s}=37^{\circ}-70^{\circ}\right)$} & & & \\
\hline All wavelenghts & $\begin{array}{c}A\left[10^{-2}\right] \\
2.25\end{array}$ & $\begin{array}{c}B_{1}\left[10^{-4}\right] \\
-9.53\end{array}$ & $\begin{array}{c}B_{2}\left[10^{-5}\right] \\
1.02\end{array}$ & $\begin{array}{c}A\left[10^{-2}\right] \\
2.03\end{array}$ & $\begin{array}{c}B_{1}\left[10^{-4}\right] \\
-7.06\end{array}$ & $\begin{array}{c}B_{2}\left[10^{-6}\right] \\
6.16\end{array}$ & $\begin{array}{c}A\left[10^{-2}\right] \\
1.99\end{array}$ & $\begin{array}{c}B_{1}\left[10^{-4}\right] \\
-5.52\end{array}$ & $\begin{array}{c}B_{2}\left[10^{-6}\right] \\
3.92\end{array}$ & & & \\
\hline
\end{tabular}

\subsection{The ratio $L_{\mathrm{r}} / E_{\text {tot }}$}

If the downward solar irradiance $E_{\text {sun }}$ and the downward radiance $L\left(0^{\circ}\right)$ have been observed, and the wind speed $W$ and solar zenith angle $\theta_{s}$ are known, then it is possible to obtain estimates of $L_{\mathrm{r}, \text { sky }}$ and $L_{\mathrm{r} \text {, sun }}$ by the polynomials in Table 5. If, in addition, $E_{\text {tot }}$ has been observed, $L_{r}$,foam can be estimated by Eq. (27). The total reflectance $L_{\mathrm{r}}$ as well as the normalized total reflectance $L_{\mathrm{r}} / E_{\mathrm{tot}}$ are then determined.

There is one objection that can be raised if one intends to apply this procedure to automatic recordings at sea, namely the problem of observing $E_{\text {sun. }}$. While $E_{\text {tot }}$ and $L\left(0^{\circ}\right)$ are easily measured by continuously recording sensors, the determination of $E_{\text {sun }}$ is not a routine operation. It can be recorded manually by simple devices or automatically by high technology instruments, but such instruments are not suitable for mounting on a ship where they are exposed to varying weather conditions. The movements of the ship represent an additional problem. Fortunately, since $E_{\text {sky }}$ is related to $L\left(0^{\circ}\right)$ by a hemispherical integral including $L\left(0^{\circ}\right)$, it is possible to estimate $E_{\text {sky }}$ from the observed $L\left(0^{\circ}\right)$ with satisfactory accuracy. The use of second order polynomials of $\theta_{s}$ to approximate the ratio $E_{\text {sky }} / L\left(0^{\circ}\right)$ at the different wavelengths results in a relative RMS error of $6 \%$ for the estimated $E_{\text {sky }}$. The polynomials for $E_{\text {sky }} / L\left(0^{\circ}\right)$ are presented in Table 5. When $E_{\text {sky }}$ has been estimated from $L\left(0^{\circ}\right)$ and $\theta_{s}, E_{\text {sun }}$ can be found by subtracting $E_{\text {sky }}$ from the observed $E_{\text {tot. }}$

The polynomials of Table 5 and Eq. (27) can now be applied to estimate the normalized reflectance towards zenith, $L_{\mathrm{r}} / E_{\mathrm{tot}}$. The complete procedure has been tested and compared to the directly calculated values of $L_{\mathrm{r}} / E_{\text {tot }}$ (Fig. 8). The RMS value of the errors by using the polynomials is $\leq 0.0001$ at all wind speeds $\leq 10 \mathrm{~m} \mathrm{~s}^{-1}$, while the relative errors are $\leq 5 \%$.

It may be pointed out that the influences of the solar zenith angle and the wavelength on the estimated ratio $L_{\mathrm{r}, \mathrm{sky}} / L\left(0^{\circ}\right)$ are rather small in our case. If we approximate the values of $L_{\mathrm{r}, \mathrm{sky}} / L\left(0^{\circ}\right)$ by the spectral mean values of Table 3 rather

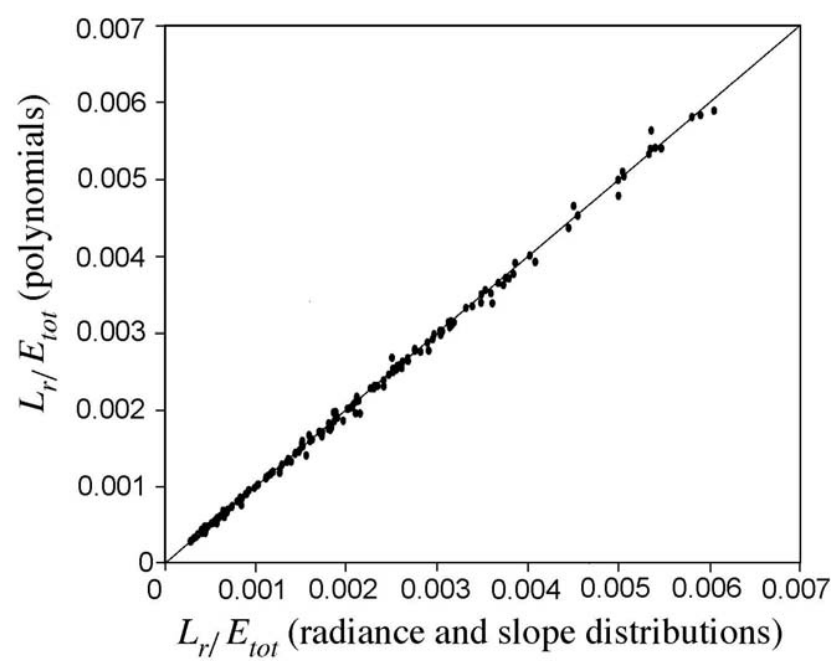

Fig. 8. The ratio $L_{\mathrm{r}} / E_{\text {tot }}$ obtained from the polynomials of Table 5 as a function of the same ratio calculated from the radiance and slope distributions, at the wavelengths 405, 450, 520, 550 and $650 \mathrm{~nm}$, and at the wind speeds 0,5 and $10 \mathrm{~m} \mathrm{~s}^{-1}$.

than by the polynomials of Table 5 , thus disregarding the solar zenith angle, the RMS value of the errors for the estimated total reflectance $L_{\mathrm{r}} / E_{\text {tot }}$ will increase only slightly, from 2.0 $6.7-8.1$ to $2.3-7.0-10.6$ in units of $10^{-5}$ for the wind speeds $0-5-10 \mathrm{~m} \mathrm{~s}^{-1}$, respectively, and as we see the error will still be $\leq 0.0001$ at all wind speeds $\leq 10 \mathrm{~m} \mathrm{~s}^{-1}$. If we also disregard the influence of wavelength on the ratio $L_{\mathrm{r} \text {,sky }} / L\left(0^{\circ}\right)$ by using the mean values of $L_{\mathrm{r}, \mathrm{sky}} / L\left(0^{\circ}\right)$ from Table 1 , the RMS value of the estimated $L_{\mathrm{r}} / E_{\mathrm{tot}}$ remains practically the same as in the last case.

It should be remembered that these errors represent the deviations between two methods based on the same input. Also, since the applied data set only represents 9 days with clear sky conditions, there may be situations that are not covered by the observations, and which could result in greater errors. 
In the present study the applied wavelengths have been $405,450,520,550$ and $650 \mathrm{~nm}$. These wavelengths are different from the channels of the satellite sensors MERIS, MODIS and SeaWiFS. However, based on the spectral distributions of $L_{\mathrm{r}} / E_{\mathrm{tot}}$ found here, it seems that linear spectral interpolation of $L_{\mathrm{r}} / E_{\mathrm{tot}}$ is a satisfactory method for obtaining values at other wavelengths.

The results at different wind speeds have mostly been presented for 0,5 and $10 \mathrm{~m} \mathrm{~s}^{-1}$. Comparison with results at other wind speeds indicates that $L_{\mathrm{r}} / E_{\mathrm{tot}}$ may be interpolated as a linear function of $W$.

\subsection{The ratio $L_{\mathrm{w}} / L_{\mathrm{r}}$}

The azimuthal mean values $L_{\mathrm{w}}^{0-}\left(\theta_{\mathrm{w}}\right)$ of the sub-surface radiance can be converted to the water-leaving radiance $L_{\mathrm{w}}$ by Eq. (32). It was observed in Sect. 2.1 that for wind speeds up to $10 \mathrm{~m} \mathrm{~s}^{-1}, 90 \%$ of the directions contributing to $L_{\mathrm{w}}$ had nadir angles $\theta_{\mathrm{w}}$ in water less than $6^{\circ}$. Within this small angular interval $L_{\mathrm{w}}^{0-}\left(\theta_{\mathrm{w}}\right)$ is practically constant. Tyler's (1960) observations of blue radiance in Lake Pend Oreille result in the value 1.03 for the ratio $L_{\mathrm{w}}^{0-}\left(10^{\circ}\right) / L_{\mathrm{w}}^{0-}\left(0^{\circ}\right)$ close to the surface. Based on linear interpolation the ratio $L_{\mathrm{w}}^{0-}\left(5^{\circ}\right) / L_{\mathrm{w}}^{0-}\left(0^{\circ}\right)$ should then have the value 1.015. Similar observations by Lundgren in the Mediterranean at a depth of 0.5-1 $\mathrm{m}$ (Aas et al., 1997) indicate values in a range from 1.00 to 1.01 for $L_{\mathrm{w}}^{0-}\left(10^{\circ}\right) / L_{\mathrm{w}}^{0-}\left(0^{\circ}\right)$, and even closer to 1.00 for $L_{\mathrm{w}}^{0-}\left(5^{\circ}\right) / L_{\mathrm{w}}^{0-}\left(0^{\circ}\right)$.

The data set of radiances and irradiances from the Oslofjord-Skagerrak area, described in Sect. 2.7, has been restricted to those 12 stations where $50 \%$ of the sky or more was free of clouds, and where $\theta_{s}$ was smaller than $76^{\circ}$. Because the instrument only records radiance from nadir, the radiance at other angles has to be estimated by other methods, like for instance the $\alpha$ model (Aas and Højerslev, 1999). This model approximates the azimuthal average $L_{u}\left(\theta_{w}\right)$ of upward radiance by the function

$L_{u}\left(\theta_{\mathrm{w}}\right)=L_{u}\left(0^{\circ}\right) \frac{1+\alpha}{1+\alpha \cos \theta_{\mathrm{w}}}$,

where $\theta_{\mathrm{w}}$ is the nadir angle in water, and $\alpha$ is defined by

$\alpha=\frac{L_{u}\left(90^{\circ}\right)}{L_{u}\left(0^{\circ}\right)}-1$.

The $Q$ factor is defined as the ratio between upward irradiance and nadir radiance, and by integrating Eq. (36) over the lower hemisphere it is readily found that

$Q=2 \pi \frac{1+\alpha}{\alpha^{2}}[\alpha-\ln (1+\alpha)]$.

Just beneath the surface $Q$ exhibited values from 3.16 to 5.80, and by combining Eqs. (36-38), the estimates of $L_{\mathrm{w}}^{0-}\left(10^{\circ}\right) / L_{\mathrm{w}}^{0-}\left(0^{\circ}\right)$ become $1.01 \pm 0.01$, and for $L_{\mathrm{w}}^{0-}\left(5^{\circ}\right) / L_{\mathrm{w}}^{0-}\left(0^{\circ}\right)$ the deviations from 1.00 are less than 0.01 . Thus the Case 2 waters of the Lake Pend Oreille and the
Oslofjord-Skagerrak area, as well as the Case 1 waters of the Mediterranean, show that $L_{\mathrm{w}}^{0-}$ is practically constant for all nadir angles equal to or less than $10^{\circ}$.

It is therefore a reasonable approximation to make the substitution $L_{\mathrm{w}}^{0-}\left(\theta_{\mathrm{w}}\right) \approx L_{\mathrm{w}}^{0-}\left(0^{\circ}\right)$ in Eq. (33). The radiance transmittance $\tau(j)$ is 0.979 when $\theta_{\mathrm{w}}$ is in the small range from $0^{\circ}$ to $10^{\circ}$. By using $n=1.340$, Eq. (33) can then be approximated by

$$
L_{w} \approx L_{\mathrm{w}}^{0-}\left(0^{\circ}\right) \frac{0.979}{1.340^{2}} \sum 2 \Delta P=0.545 L_{\mathrm{w}}^{0-}\left(0^{\circ}\right),
$$

since the sum of all probabilities is 1 (Eq. 20). It should be noted that the ratio $L_{\mathrm{w}} / L_{\mathrm{w}}^{0-}\left(0^{\circ}\right)$ is a constant value, independent of the wavelength and the wind speed. Aas et al. (2009) obtained the value 0.546 for this ratio by a different procedure, as an approximation for a flat sea.

The normalized water-leaving radiances $L_{\mathrm{w}} / E_{\text {tot }}$ have been calculated, and the results have been extrapolated and interpolated to the wavelengths used in this paper. The wind speed at the stations ranged from 1.5 to $7.5 \mathrm{~m} \mathrm{~s}^{-1}$, with an average value and standard deviation equal to 4 and $2 \mathrm{~m} \mathrm{~s}^{-1}$, respectively. For each station with a value of $L_{\mathrm{w}} / E_{\mathrm{tot}}$ the atmospheric data that were closest with regard to $\theta_{s}$ were chosen, and the corresponding value of $L_{\mathrm{r}} / E_{\text {tot }}$ was then calculated for the same wind speed. The ratio between $L_{\mathrm{w}} / E_{\mathrm{tot}}$ and $L_{\mathrm{r}} / E_{\text {tot }}$ may then provide a tentative estimate of $L_{\mathrm{w}} / L_{\mathrm{r}}$.

The results are presented in Table 6, which shows that $L_{\mathrm{w}} / L_{\mathrm{r}}$ at the chosen stations on an average varies spectrally from 0.5 to in the UV to 0.7 in the red, with a maximum of 2 in the blue-green part. This means that the reflected radiance cannot be disregarded at any wavelength within the spectral range $405-650 \mathrm{~nm}$, and that the contribution from the waterleaving radiance to the total upward radiance should not be disregarded either. That is, neither of the contributions from the surface of the sea to the radiance directed towards the zenith can be disregarded within this spectral range in the Oslofjord-Skagerrak area. The values displayed in Table 6 fit well with the simulations of Mobley (1999, Fig. 12), except at the wavelengths 405 and $450 \mathrm{~nm}$, where the present values of $L_{\mathrm{w}} / L_{\mathrm{r}}$ are lower, due to the significant influence of yellow substance in our waters.

\section{Summary and conclusions}

The relationship between wind speed and mean square slope found by Cox and Munk (1954a, b) has been used with a one-dimensional Gaussian probability function for the surface slope in order to calculate the radiance from sky and sun reflected towards the zenith. The contribution $L_{\mathrm{r} \text {,sky }}$ from the reflected sky radiance was expressed by Eq. (19), and the contribution $L_{\mathrm{r}, \text { sun }}$ from the reflected sun glints by Eq. (22). The special contribution of reflected radiance from white-

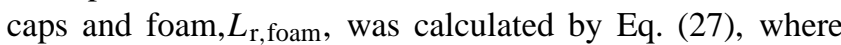
the foam is assumed to act as a Lambertian emitter (constant 
Table 6. Estimates of the ratio between water-leaving and reflected radiances. $W=1.5-7.5 \mathrm{~m} \mathrm{~s}^{-1}, \theta_{s}=37^{\circ}-52^{\circ}$.

\begin{tabular}{llccc}
\hline Wavelength[nm] & & $L_{\mathrm{r}} / E_{\text {tot }}\left[10^{-3}\right]$ & $L_{\mathrm{w}} / E_{\text {tot }}\left[10^{-3}\right]$ & $L_{\mathrm{w}} / L_{\mathrm{r}}$ \\
\hline \multirow{2}{*}{405} & Mean value & 2.8 & 1.3 & 0.5 \\
\multirow{2}{*}{450} & Standard deviation & 1.1 & 0.7 & 0.3 \\
& Mean value & 2.7 & 2.0 & 0.8 \\
520 & Standard deviation & 1.0 & 1.1 & 0.3 \\
& Mean value & 2.1 & 2.9 & 2.0 \\
550 & Standard deviation & 1.2 & 1.1 & 1.4 \\
\multirow{2}{*}{650} & Mean value & 2.4 & 2.9 & 1.4 \\
& Standard deviation & 0.9 & 1.1 & 0.7 \\
& Mean value & 1.7 & 0.8 & 0.7 \\
& Standard deviation & 1.1 & 0.6 & 0.6 \\
\hline
\end{tabular}

radiance) with a spectrally constant reflectance. The input data have been the tabulated values of sky radiance, solar irradiance and total irradiance presented by Høkedal and Aas (1998). The applied data set consisted of 52 sub-sets of angular distributions of sky radiance and direct solar irradiance in the Oslo region, at the wavelengths 405, 450, 520, 550 and $650 \mathrm{~nm}$, and with solar zenith angles in the range $37^{\circ}-76^{\circ}$. From the calculated values of $L_{\mathrm{r} \text {, sky }}, L_{\mathrm{r} \text {, sun }}$ and $L_{\mathrm{r} \text {,foam }}$ the total reflected radiance $L_{\mathrm{r}}$ could then be obtained.

Table 1 shows that the ratio $L_{\mathrm{r}} / L\left(0^{\circ}\right)$ between the radiance reflected towards the zenith and the diffuse sky radiance incident from the zenith has no constant value for wind speeds in the range $W=0-10 \mathrm{~m} \mathrm{~s}^{-1}$. When $W=0 \mathrm{~m} \mathrm{~s}^{-1}$, the mean value of the ratio plus/minus the standard deviation is $0.0215 \pm 0.0003$, while the corresponding numbers for $W=10 \mathrm{~m} \mathrm{~s}^{-1}$ are $0.0784 \pm 0.0575$. The mean value of the ratio has then increased by a factor of 3.7. This is due to the sun glitter that for certain solar zenith angles and wind speeds has a significant impact on the radiance reflected towards the zenith.

The results of Table 2 imply that the assumption of specular flat ocean reflection expressed by Eq. (35) is only valid in our case with a zenith-directed reflectance and solar zenith angles in the range $\theta_{s} \geq 37^{\circ}$ when there is practically no wind, that is $W<2 \mathrm{~m} \mathrm{~s}^{-1}$. At wind speeds up to $5 \mathrm{~m} \mathrm{~s}^{-1}$ Eq. (35) can only be applied to a restricted range of $\theta_{s}$ where the lower limit of the range increases with increasing wind speed. When $W=5 \mathrm{~m} \mathrm{~s}^{-1}, \theta_{s}$ has to be $65^{\circ}$ or greater in order to avoid significant effects of sun glitter in the zenith direction. The results of Table 1 show that the contribution of foam-reflected radiance should preferably be taken into account whenever $W \geq 5 \mathrm{~m} \mathrm{~s}^{-1}$, since it may then be in the range of $1-100 \%$ of $L_{\mathrm{r}, \text { sky }}$.

In order to obtain simple but accurate methods for the estimation of the reflected radiance $L_{\mathrm{r}}$, the radiance has to be separated into the three contributions $L_{\mathrm{r}, \mathrm{sky}}, L_{\mathrm{r} \text {,sun }}$, and

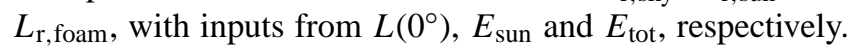
Equation (27) provides a very simple relationship between
$L_{\mathrm{r} \text {,foam }}, E_{\text {tot }}$ and $W$. The ratio $L_{\mathrm{r}, \text { sun }} / E_{\text {sun }}$ can be approximated by best-fit polynomials on the form $A+B_{1} \theta_{s}+B_{2}$ $\theta_{s}^{2}$, where $A, B_{1}$ and $B_{2}$ are constants, and the results for the wind speeds 3,5 and $10 \mathrm{~m} \mathrm{~s}^{-1}$ are presented in Table 5 and Fig. 7. These relationships are independent of wavelength. The ratio $L_{\mathrm{r}, \mathrm{sky}} / L\left(0^{\circ}\right)$ has been described by similar polynomials for the different wavelengths and wind speeds, as shown by Table 5 . The ratio can also be estimated by applying the mean values presented in Tables 1 and 3. Because there is no constant ratio between the different inputs at a given wavelength, wind speed and solar zenith angle, a common normalizing quantity for the three contributions to $L_{\mathrm{r}}$ is not possible. It has for instance been shown by Fig. 6 that the ratio $E_{\text {sun }} / E_{\text {sky }}$ varies in an unpredictable way due to different optical conditions of the atmosphere.

While the measurements of $L\left(0^{\circ}\right)$ and $E_{\text {tot }}$ are standard operations, the separation of $E_{\text {tot }}$ into $E_{\text {sky }}$ and $E_{\text {sun }}$ is not. It has been demonstrated, however, that it is possible to estimate $E_{\text {sky }}$ from the observed $L\left(0^{\circ}\right)$ with a relative RMS error of $6 \%$, by using second order polynomials of $\theta_{s}$. The polynomials for $E_{\text {sky }} / L\left(0^{\circ}\right)$ are presented in Table 5 . When $E_{\text {sky }}$ has been estimated from $L\left(0^{\circ}\right)$ and $\theta_{s}, E_{\text {sun }}$ can be found by subtracting $E_{\text {sky }}$ from the observed $E_{\text {tot }}$.

Thus from known values of $L\left(0^{\circ}\right), E_{\mathrm{tot}}, W$ and $\theta_{s}$, the reflected radiance $L_{\mathrm{r}}$ can be determined as described above. The results of this procedure have been presented in Fig. 8 and Table 7. The RMS values of the errors are $\leq 0.0001$ at all wind speeds $\leq 10 \mathrm{~m} \mathrm{~s}^{-1}$, while the RMS errors relative to the mean values of $L_{\mathrm{r}} / E_{\text {tot }}$ are $\leq 5 \%$, which should be acceptable deviations. Table 7 shows the spectral results for the method where only $L\left(0^{\circ}\right)$ is used as a reference, and the method where $L\left(0^{\circ}\right)$ is supplied by observations of $E_{\text {tot }}$. We see that in our case with zenith-reflected radiance and significant contributions from sun glints at the studied wind speeds, satisfactory results can only be obtained by the latter method.

Values of the ratio between the water-leaving radiance and the reflected radiance, $L_{\mathrm{w}} / L_{\mathrm{r}}$, have been tentatively estimated from field observations of $L_{\mathrm{w}} / E_{\mathrm{tot}}$ and calculated 
Table 7. Comparison of mean values and RMS errors of $L_{\mathrm{r}} / L\left(0^{\circ}\right)$ and $L_{\mathrm{r}} / E_{\text {tot }}$ in units of $10^{-4}$ by different methods for estimating the reflected radiance.

\begin{tabular}{|c|c|c|c|c|c|}
\hline Method & Quantity & Wavelength [nm] & $W=0 \mathrm{~m} \mathrm{~s}^{-1}$ & $W=5 \mathrm{~m} \mathrm{~s}^{-1}$ & $W=10 \mathrm{~m} \mathrm{~s}^{-1}$ \\
\hline & $\begin{array}{l}\text { Mean value of } \\
L_{\mathrm{r}} / L\left(0^{\circ}\right)\end{array}$ & $\begin{array}{l}405 \\
450 \\
520 \\
550 \\
650\end{array}$ & $\begin{array}{l}213 \\
215 \\
215 \\
216 \\
216\end{array}$ & $\begin{array}{l}304 \\
292 \\
364 \\
292 \\
470\end{array}$ & $\begin{array}{l}499 \\
535 \\
755 \\
738 \\
1314\end{array}$ \\
\hline $\begin{array}{l}\text { Estimating } L_{\mathrm{r}} / L\left(0^{\circ}\right) \text { from } L_{\mathrm{r}, \text { sky }} / L\left(0^{\circ}\right) \text {, } \\
\left.L_{\mathrm{r} \text {,sun }} / L\left(0^{\circ}\right)\right) \text { and } L_{\mathrm{r} \text {,foam }} / L\left(0^{\circ}\right) \text { at each } \\
\text { wavelength and wind speed }\end{array}$ & $\begin{array}{l}\text { RMS error of } \\
\text { the estimated } \\
L_{\mathrm{r}} / L\left(0^{\circ}\right)\end{array}$ & $\begin{array}{l}405 \\
450 \\
520 \\
550 \\
650\end{array}$ & $\begin{array}{l}4 \\
1 \\
3 \\
2 \\
2\end{array}$ & $\begin{array}{l}44 \\
46 \\
112 \\
37 \\
198\end{array}$ & $\begin{array}{l}102 \\
136 \\
281 \\
183 \\
563\end{array}$ \\
\hline & $\begin{array}{l}\text { Mean value of } \\
L_{\mathrm{r}} / E_{\mathrm{tot}}\end{array}$ & $\begin{array}{l}405 \\
450 \\
520 \\
550 \\
650\end{array}$ & $\begin{array}{l}20.6 \\
16.3 \\
11.6 \\
9.2 \\
5.0\end{array}$ & $\begin{array}{l}27.9 \\
21.4 \\
17.5 \\
12.5 \\
10.0\end{array}$ & $\begin{array}{l}44.2 \\
36.6 \\
33.3 \\
26.5 \\
25.9\end{array}$ \\
\hline $\begin{array}{l}\text { Estimating } L_{\mathrm{r}} / E_{\text {tot }} \text { from } L_{\mathrm{r}, \mathrm{sky}} / L\left(0^{\circ}\right) \text {, } \\
L_{\mathrm{r}, \text { sun }} / E_{\text {sun }} \text { and } L_{\mathrm{r} \text {,foam }} / E_{\text {tot }} \text { at each wave- } \\
\text { length and wind speed }\end{array}$ & $\begin{array}{l}\text { RMS error of } \\
\text { the estimated } \\
L_{\mathrm{r}} / E_{\mathrm{tot}}\end{array}$ & $\begin{array}{l}405 \\
450 \\
520 \\
550 \\
650\end{array}$ & $\begin{array}{l}0.4 \\
0.0 \\
0.2 \\
0.1 \\
0.1\end{array}$ & $\begin{array}{l}1.1 \\
0.5 \\
0.6 \\
0.6 \\
0.4\end{array}$ & $\begin{array}{l}0.9 \\
0.6 \\
0.8 \\
1.0 \\
0.6\end{array}$ \\
\hline
\end{tabular}

values of $L_{\mathrm{r}} / E_{\mathrm{tot}}$. For the calculation of $L_{\mathrm{r}} / E_{\mathrm{tot}}$ an atmospheric data set was chosen where $\theta_{s}$ was as close to the corresponding angle for $L_{\mathrm{w}} / E_{\mathrm{tot}}$ as possible, and the calculation was made with the same wind speed as for $L_{\mathrm{w}} / E_{\text {tot }}$. The wind speed at the selected stations varied from 1.5 to $7.5 \mathrm{~m} \mathrm{~s}^{-1}$ and the solar zenith angle from $37^{\circ}$ to $52^{\circ}$. The results, presented in Table 6, show that within the spectral range $405-650 \mathrm{~nm}$ neither of the contributions $L_{\mathrm{w}}$ or $L_{\mathrm{r}}$ to the zenith-directed radiance can be disregarded relative to the other one in the Oslofjord-Skagerrak area.

This paper has discussed the case where the viewing direction has been directed towards the nadir. If such recordings are made from a ship, the sensor must be mounted on a bar at a long distance from the rail, on the same side as the sun, in order to avoid the shadowing and reflecting effects of the ship. If the ship is at rest, a position in the direction backwards from the stern minimizes the ship's influence. If the ship is moving, the wake of the ship must be avoided, because the reflecting properties of the wake are quite different from those of the sea around it. In addition to the nadir radiance from the sea, the zenith radiance from the sky as well as the downward irradiance must be recorded, and especially the irradiance sensor should be mounted as high as possible, to avoid the influence of the ship building and masts. If the sensor is mounted up in a mast, its position should be as long away from the mast as practically possible, to avoid the shadow of the mast.
However, ship-mounted sensors usually have non-nadir viewing angles in order to avoid both the influence of the ship within the field-of-view and the sun glitter, but unfortunately the sensors on moving ferries are apt to experience very varying azimuth angles with regard to the sun. Accordingly it will be very useful to have simple methods for estimating the different types of reflected radiance: from the sky, sun and foam. In an on-going co-project with the Norwegian Institute for Water Research other angles than the nadir direction are studied. It is considered if observations in the ultraviolet and near infrared, where the water-leaving radiance in coastal water usually will be very small compared to the surface-reflected radiance, can be utilized for correction purposes. It has been demonstrated in this paper that if the ratios $L_{\mathrm{r}, \text { sky }} / L\left(0^{\circ}\right)$ and $L_{\mathrm{r} \text {, sun }} / E_{\text {sun }}$ are known at one wavelength, their values at other wavelengths can be estimated. This is valid for the zenith-directed reflectance, and it may be applied to other directions as well (Morel, 1980; Zibordi et al., 2002). Finally it should be stated that the validity of the applied Cox-Munk model (1954a, b) for the surface slopes as well as the Eq. (27) for the reflectance of foam, based on the results of Monahan and O'Muircheartaigh (1980) and Koepke (1984), have not been tested by independent methods in our area of investigation. 
Acknowledgements. The author is due thanks to the topical editor and the referees for their constructive comments and suggestions.

Edited by: P. Cipollini

\section{References}

Aas, E.: Calibration of a marine radiance and colour index meter, Rep. No. 87, Dept. Geophys., Univ. Oslo, 1993.

Aas, E. and Høkedal, J.: Reflection of spectral sky irradiance on the surface of the sea and related properties, Remote Sens. Environ., 70, 181-190, 1999.

Aas, E. and Højerslev, N. K.: Analysis of underwater radiance observations: Apparent optical properties and analytic functions describing the angular radiance distribution, J. Geophys. Res., 104, 8015-8024, 1999.

Aas, E., Højerslev, N. K. and Høkedal, J.: Conversion of subsurface reflectances to above-surface MERIS reflectance, Int. J. Remote Sens., 30, 5767-5791, 2009.

Aas, E., Højerslev, N. K. and Lundgren, B.: Spectral irradiance, radiance and polarization data from the Nordic Cruise in the Mediterranean Sea during June-July 1971, Rep. No. 102, Dept. Geophys., Univ. Oslo, Norway, 1997.

Aas, E. and Korsbø, B.: Self-shading effect by radiance meters on upward radiance observed in coastal waters, Limn. Oceanogr., 42, 968-974, 1997.

Abramowitz, M. and Stegun, I. A.: Handbook of Mathematical Functions, Dover Publ., New York, 1970.

Adams, J. T., Aas, E., Højerslev, N. K., and Lundgren, B.: Comparison of radiance and polarization values observed in the Mediterranean Sea and simulated in a Monte Carlo model, Appl. Opt., 41, 2724-2733, 2002.

Austin, R. W.: The remote sensing of spectral radiance from below the ocean surface, edited by: Jerlov, N. G. and Steeman Nielsen, E.: Optical Aspects of Oceanography, Academic Press, London, 317-344, 1974.

Cox, C. and Munk, W.: Statistics of the sea surface derived from sun glitter, J. Mar. Res., 13, 198-227, 1954a.

Cox, C. and Munk, W.: The measurements of the roughness of the sea surface from photographs of the sun's glitter, J. Opt. Soc. Am., 44, 838-850, 1954b.

Deschamps, P.-Y., Fougnie, B., Frouin, R., Lecomte, P., and Verwaerde, C.: SIMBAD: a field radiometer for satellite ocean-color validation, Appl. Opt., 43, 4055-4069, 2004.

Fougnie, B., Frouin, R., Lecomte, P., and Deschamps, P.-Y.: Reduction of skylight reflection effects in the above-water measurement of diffuse marine reflectance, Appl. Opt., 38, 3844-3856, 1999.

Frouin, R., Schwindling, M., and Deschamps, P.-Y.: Spectral reflectance of sea foam in the visible and near-infrared: In situ measurements and remote sensing implications, J. Geophys. Res., 101, 14361-14371, 1996.

Gordon, H. R. and Ding, K.: Self-shading of in-water optical instruments, Limn. Oceanogr., 37, 491-500, 1992.

Gordon, H. R. and Wang, M.: Surface-roughness considerations for atmospheric correction of ocean color sensors I: The Rayleighscattering component, Appl. Opt., 31, 4247-4260, 1992a.
Gordon, H. R. and Wang, M.: Surface-roughness considerations for atmospheric correction of ocean color sensors II: Error in the retrieved water-leaving radiance, Appl. Opt., 31, 4261-4267, $1992 b$.

Hooker, S. B., Lazin, G., Zibordi, G., and McLean, S.: An evaluation of above- and in-water methods for determining waterleaving radiances, J. Atmos. Oceanic Techn., 19, 486-515, 2002.

Højerslev, N. K. and Aas, E.: Spectral irradiance, radiance and polarization in blue Western Mediterranean waters, in Ocean Optics XIII, Proc., 22-25 October 1996, Halifax, Canada, SPIE Vol. 2963, 138-147, 1997.

Høkedal, J. and Aas, E.: Observations of spectral sky radiance and solar irradiance, Rep. No. 103, Dept. Geophys., Univ. Oslo, Norway, 1998.

Kattawar, G. W. and Adams, C. N.: Errors in radiance calculations induced by using scalar rather than Stokes vector theory in a realistic atmosphere-ocean system, in Ocean Optics X, Proc., 16-18 April 1990, Orlando, Florida, SPIE Vol. 1302, 2-12, 1990.

Koepke, P.: Effective reflectance of oceanic whitecaps, Appl. Opt., 23, 1816-1824, 1984.

Kokhanovsky, A. A.: Spectral reflectance of whitecaps, J. Geophys. Res., 109, C05021, doi:10.1029/2003JC002177, 2004.

Lauscher, F.: Sonnen- und Himmelstrahlung im Meer und in Gewässern, edited by Linke, F. and Möller, F.: Handbuch der Geophysik, 8, Physik der Atmosphäre, Gebrüder Borntraeger, Berlin, Germany, 723-768, 1955.

Lundgren, B.: On the polarization of the daylight in the sea, Rep. No. 17, Dept. Phys. Oceanogr., Univ. Copenhagen, 1971.

Mobley, C. D.: Estimation of the remote-sensing reflectance from above-surface measurements, Appl. Opt., 38, 7442-7455, 1999.

Monohan, E. C.: Oceanic whitecaps, J. Phys. Oceanogr., 1, 139144, 1971.

Monohan, E. C. and O'Muircheartaigh, I. G.: Optimal power-law description of oceanic whitecap coverage dependence on wind speed, J. Phys. Oceanogr., 10, 2094-2099, 1980.

Monohan, E. C. and O'Muircheartaigh, I. G.: Improved statement of the relationship between surface wind speed and oceanic whitecap coverage as required for the interpretation of satellite data, edited by: Gower, J. F. R.: Oceanography from space, Plenum, New York, 751-755, 1981.

Monohan, E. C. and O'Muircheartaigh, I. G.: Whitecaps and the passive remote sensing of the ocean surface, Int. J. Remote Sens. 7, 627-642, 1986.

Moore, K. D., Voss, K. J. and Gordon, H. R.: Spectral reflectance of whitecaps: Instrumentation, calibration, and performance in coastal waters, J. Atmos. Oceanic Technol., 15, 496-509, 1998.

Moore, K. D., Voss, K. J., and Gordon, H. R.: Spectral reflectance of whitecaps: Their contribution to water-leaving radiance, J. Geophys. Res., 105, 6493-6499, 2000.

Morel, A.: In-water and remote measurements of ocean color, Bound.-Layer Meteor., 18, 177-201, 1980.

Mueller, J. L., Davis, C., Arnone, R., Frouin, R., Carder, K., Lee, Z. P., Steward, R. G., Hooker, S., Mobley, C. D., and McLean, S.: Above-water radiance and remote sensing reflectance measurement and analysis protocols, in: Ocean Optics Protocols for Satellite Ocean Color Sensor Validation, Revision 4, Volume III: Radiometric Measurements and Data Analysis Protocols, NASA/TM-2003-21621/Rev-Vol III, 21-31, 2003.

Munk, W.: An inconvenient sea truth: Spread, steepness, and skew- 
ness of surface slopes, Ann. Rev. Mar. Sci., 1, 377-415, 2009.

Nicolas, J.-M., Deschamps, P. Y., and Frouin, R.: Spectral reflectance of oceanic whitecaps in the visible and near infrared: Aircraft measurements over open ocean, Geophys. Res. Lett., 28, 4445-4448, 2001.

Preisendorfer, R. W. and Mobley, C. D.: Albedos and glitter patterns of a wind- roughened sea surface, J. Phys. Oceanogr., 16, 12931316, 1986.

Ruddick, K. G., De Cauwer, V., and Park, Y.-J.: Seaborne measurements of near infrared water-leaving reflectance: The similarity spectrum for turbid waters, Limnol. Oceanogr., 51, 1167-1179, 2006.

Tyler, J. E.: Radiance distribution as a function of depth in an underwater environment, Bull. Scripps Inst. Oceanogr., 7, 363-412, Univ. Cal., La Jolla, Cal., 1960.

Walker, R. E.: Marine Light Field Statistics, Wiley, New York, 1994.

Whitlock, C. H., Bartlett, D. S., and Gurganus, E. A.: Sea foam reflectance and influence on optimal wavelength for remote sensing of ocean aerosols, Geophys. Res. Lett., 9, 719-722, 1982.
Wu, J.: Oceanic whitecaps and sea state, J. Phys. Oceanogr., 9, 1064-1068, 1979.

Zibordi, G. and Ferrari, G. M.: Instrument self-shading in underwater optical measurements: experimental data, Appl. Opt., 34, 2750-2754, 1995.

Zibordi, G., Hooker, S. B., Berthon, J. F., and D'Alimonte, D.: Autonomous above- water radiance measurements from an offshore platform: a field assessment experiment, J. Atmos. Ocean. Tech., 19, 808-819, 2002.

Zibordi, G., Mélin, F., Hooker, S. B., D’Alimonte, D., and Holben, B.: An autonomous above-water system for the validation of ocean color radiance data, IEEE Trans. Geosc. Remote Sens., 42, 401-415, 2004.

Zibordi, G., Holben, B., Slutsker, I., Giles, D., D'Alimonte, D., Mélin, F., Berthon, J.- F., Vandemark, D., Feng, H., Schuster, G., Fabbri, B. E., Kaitala, S., and Seppälä, J.: AERONET-OC: A network for the validation of ocean color primary products, J. Atmos. Ocean. Tech., 26, 1634-1651, 2009. 